\title{
Real World and Tropical Cyclone World. Part I: High-Resolution Climate Model Verification
}

\author{
S. SHARMILA \\ Centre for Applied Climate Sciences, University of Southern Queensland, Toowoomba, Queensland, and School \\ of Earth Sciences, University of Melbourne, Parkville, Australia \\ K. J. E. WALSH \\ School of Earth Sciences, University of Melbourne, Parkville, Australia \\ M. THATCHER \\ CSIRO Oceans and Atmosphere, Aspendale, Australia \\ S. WALES \\ School of Earth Sciences, University of Melbourne, Parkville, and ARC Centre of Excellence for \\ Climate System Science, Canberra, Australia \\ S. UTEMBE \\ Environmental Protection Authority Victoria, Melbourne, and School of Earth Sciences, University of \\ Melbourne, Parkville, Australia
}

(Manuscript received 28 January 2019, in final form 27 October 2019)

\begin{abstract}
Recent global climate models with sufficient resolution and physics offer a promising approach for simulating real-world tropical cyclone (TC) statistics and their changing relationship with climate. In the first part of this study, we examine the performance of a high-resolution $(\sim 40-\mathrm{km}$ horizontal grid) global climate model, the atmospheric component of the Australian Community Climate and Earth System Simulator (ACCESS) based on the Met Office Unified Model (UM8.5) Global Atmosphere (GA6.0). The atmospheric model is forced with observed sea surface temperature, and 20 years of integrations (1990-2009) are analyzed for evaluating the simulated TC statistics compared with observations. The model reproduces the observed climatology, geographical distribution, and interhemispheric asymmetry of global TC formation rates reasonably well. The annual cycle of regional TC formation rates over most basins is also well captured. However, there are some regional biases in the geographical distribution of TC formation rates. To identify the sources of these biases, a suite of model-simulated large-scale climate conditions that critically modulate TC formation rates are further evaluated, including the assessment of a multivariate genesis potential index. Results indicate that the model TC genesis biases correspond well to the inherent biases in the simulated large-scale climatic states, although the relative effects on TC genesis of some variables differs between basins. This highlights the model's mean-state dependency in simulating accurate TC formation rates.
\end{abstract}

Supplemental information related to this paper is available at the Journals Online website: https://doi.org/10.1175/JCLI-D-190078.s1.

Corresponding author: K. J. E. Walsh, kevin.walsh@unimelb. edu.au

\section{Introduction}

The ability of climate models to simulate the observed climatology of tropical cyclones (TCs) has gradually improved over time (e.g., Camargo and Wing 2016). While climate models with horizontal resolutions of 
about $100 \mathrm{~km}$ can simulate tropical lows with some of the characteristics of TCs, finer-resolution models are essential in order to generate a more accurate simulation of the geographical distribution of TC formation and occurrence due to the improved representation of topography in fineresolution models and the associated improvement in the simulation of large-scale climate variables. The climate model is one of the most important tools in developing and testing our understanding of the relationship between climate and TCs, and particularly important in the absence of an accepted quantitative climate theory of TC formation (e.g., Walsh 2019). Finer-resolution climate models are now able to generate a reasonable simulation of the observed geographic pattern of TC formation along with its interannual variability (e.g., Bell et al. 2014; Murakami et al. 2015; Wehner et al. 2017; Yoshida et al. 2017). In general, global annual TC formation rates can now be well simulated, although there are remaining issues with reliable simulation of the formation rates in some TC formation basins, particularly in the North Atlantic basin (Shaevitz et al. 2014). Nevertheless, these models are valuable tools for conducting experiments where climate variables are modified and the changes in the model simulation of TC formation are analyzed, as a way of improving our understanding of the variables that are crucial for TC formation.

Such climate model experiments include examining the ability of climate models to perform seasonal predictions of TC formation (Camargo et al. 2007a, 2010; Vitart et al. 2014); idealized aquaplanet experiments (Hayashi and Sumi 1986; Merlis et al. 2013; Ballinger et al. 2015; Chavas et al. 2017); and estimates of the effect of climate change on TCs (Knutson et al. 2010; Walsh et al. 2016; Camargo and Wing 2016). In all cases, it is important that the starting point for such a series of experiments is a well-validated model that increases our confidence that the response of the model's TC climatology to imposed climate variations will likely mimic that seen in observations. The main purpose of the first part of this two-part paper is that it provides the verification of the climate model quality required for the results of the second part to have any credibility.

In the second part of the paper (Walsh et al. 2019), we move on to employ this validated modeling system to conduct some experiments on the relationship between climate and TCs. We use a combination of idealized SST specifications, from a simple constant SST aquaplanet to meridionally varying SST specifications. In this second paper, a more complete review is contained of previous work on aquaplanet experiments on TC formation. The primary motivation of this work is to transform the climate model from a simulated version of the real world, as represented in this first part of the paper, to the "tropical cyclone world," where factors that inhibit vortex formation are removed, where possible
(Khairoutdinov and Emanuel 2013). For example, at a minimum, TC world simulations would have no land, as the presence of land can inhibit TC formation. The model would require SSTs to be specified above the threshold for TC formation in the simulated climate (e.g., Merlis et al. 2013). The model would have little or no mean vertical wind shear (e.g., Tang and Emanuel 2010). The influence of each of these changes on the simulated tropical cyclone formation rate would be assessed, using a series of diagnostics as established for the current climate simulation described in the current paper. The goal is to relate changes in TC formation quantitatively to changes in climate variables, using a series of extreme climate experiments to amplify the signals indicating these relationships in the climate system.

In this first part of the two-part paper, we present an assessment of a new climate modeling system, with an emphasis on evaluating the present-climate TC climatology and associated large-scale climate conditions. Section 2 provides an overview of the model and the data and methods used to analyze its output, section 3 shows the relevant results, and section 4 provides some concluding remarks on the model evaluation.

\section{Model, data, and method}

\section{a. ACCESS model and simulation}

We use the atmospheric component of a state-of-the-art global climate model, the Australian Community Climate and Earth System Simulator coupled general circulation model (ACCESS) based on the UK Met Office Unified Model (UM v8.5) Global Atmosphere (GA6.0) (Walters et al. 2017), denoted here simply as ACCESS. The model includes a dynamical core with a semi-implicit semiLagrangian formulation, a comprehensive suite of physical parameterizations split into slow processes (radiation, large-scale precipitation, and gravity wave drag) and fast processes (atmospheric boundary layer, turbulence, convection, and land surface coupling), including the prognostic cloud fraction and prognostic condensate (PC2) scheme (Wilson et al. 2008). The model also uses the radiation scheme of Edwards and Slingo (1996), a boundary layer scheme that represents mixing over the full depth of the troposphere (Lock et al. 2000), and a community land surface model, the Joint UK Land Environment Simulator (JULES; Best et al. 2011). More model details can be found in Walters et al. (2017).

The model is run in atmosphere-only mode with specified observed sea surface temperatures (SSTs) at a horizontal resolution of $0.5625^{\circ}$ longitude $\times 0.375^{\circ}$ latitude $(\sim 40 \mathrm{~km})$ with 17 vertical levels. The interannually varying SSTs used to force the atmospheric model are taken 
from the AMIP-II experiment (Kanamitsu et al. 2002). The high-resolution version of the ACCESS model was developed specifically for this study. The ACCESS model is integrated using AMIP-II SSTs from 1 September 1988 to 31 December 2010, and model outputs are saved with a 6-h time interval. The initial few months of simulations were discarded as a model spinup, and a period of 20 years (1990-2009) of model simulation is considered for evaluating the model performance in simulating real-world TC climatology in this study.

Previous climatological simulations of TC formation using specified observed SSTs were undertaken with a previous version of the Met Office Unified Model (version GA3.0) by Roberts et al. (2015), using horizontal resolution as fine as about $25 \mathrm{~km}$. They found that numbers of simulated TCs increased with finer horizontal resolution. Some changes in the formulation of the Unified Model have occurred since then that could modify the simulated TC climatology, as detailed in Walters et al. (2017). There has been an increase in the specified rate of entrainment for deep convection, which was shown to reduce errors in simulated TC intensities by making them more intense. A major change was the introduction of a new dynamical core [Even Newer Dynamics for General Atmospheric Modelling of the Environment (ENDGame); Wood et al. 2014], which has improved the model simulation, including its simulation of TCs (Reed et al. 2015).

\section{b. TC detection algorithm}

The simulated TC-like vortices are detected and tracked using a modified version of the CSIRO cyclone tracking algorithm (Horn et al. 2014). This tracking method imposes a set of threshold physical criteria that need to be satisfied before a low pressure system can be declared a TC. The following criteria are used to detect and track TCs; the text is derived from Horn et al. (2014), with some minor modifications:

- An absolute value of 850-hPa cyclonic vorticity greater than $1 \times 10^{-5} \mathrm{~s}^{-1}$. This criterion is used to eliminate a large number of points of weak vorticity that are not associated with tropical cyclones.

- A closed pressure minimum within a distance in both the $x$ and $y$ directions of $350 \mathrm{~km}$ from a point satisfying condition 1 above. This distance is chosen empirically to give a good geographical association between vorticity maxima and pressure minima. This minimum pressure value is taken as the center of the storm.

- A mean wind speed in the region $700 \mathrm{~km} \times 700 \mathrm{~km}$ square around the center of the storm at $850 \mathrm{hPa}$ is greater than at $300 \mathrm{hPa}$.

- Maximum 10-m wind speeds exceeding a resolutiondependent value as specified in Walsh et al. (2007).
Here, the value chosen for a model with a horizontal resolution of $40 \mathrm{~km}$ is $>16.5 \mathrm{~m} \mathrm{~s}^{-1}$.

- Finally, these detection criteria must be satisfied for a period of $24 \mathrm{~h}$ for a TC to be declared.

The description of the analysis method and region definitions follows that of Sharmila and Walsh (2017), with some minor modifications as described in this paragraph. The simulated TC formation rate or TC genesis (TCG) frequency is defined as the number of tropical storms that exceed a maximum $10-\mathrm{m}$ wind speed of $16.5 \mathrm{~m} \mathrm{~s}^{-1}$. The location of TCG is identified based on the position of the tropical storms at which the maximum 10-m wind speed first exceeds $16.5 \mathrm{~m} \mathrm{~s}^{-1}$, and the TCG distribution is computed per $4^{\circ} \times 4^{\circ}$ grid box per year. The TCs formed within the latitudes $30^{\circ} \mathrm{S}-30^{\circ} \mathrm{N}$ are considered in this study. The analysis considers the six main oceanic regions displaying TC development (Table 1), namely the western Pacific (WP), eastern Pacific (EP), North Atlantic (NA), north Indian Ocean (NI), south Indian Ocean (SI), and South Pacific (SP) within the tropical domain $\left(30^{\circ} \mathrm{S}-30^{\circ} \mathrm{N}\right)$. Generally, around $70 \%$ of annual TCs form during the peak TC season in almost all basins. We have used both annual and peak TC seasons of each basin, which are selected based on maximum TC activity. This typically occurs during July-October (JASO) in the WP, July-September (JAS) in the EP, August-October (ASO) for the NA, October-December (OND) for the NI, and January-March (JFM) for both the SI and SP.

\section{c. Data for verification}

The model TC characteristics are compared with the observed TC best track data from IBTrACS (Knapp et al. 2010). To evaluate the model's simulation of observed large-scale atmospheric climate conditions, we compare with the ERA-Interim reanalysis (Dee et al. 2011), while for precipitation, monthly data from the Global Precipitation Climatology Project (GPCP v2.3) are employed (Adler et al. 2003). We have interpolated the model output to a $1.5^{\circ} \times 1.5^{\circ}$ grid, for comparison with reanalysis data.

To assess the climate controls on simulated TCG frequency, we evaluate monthly data of a suite of largescale climate conditions that influence the TC formation rates (Sharmila and Walsh 2017). For instance, we use vertical wind shear (VWS), relative vorticity (RVor), relative humidity ( $\mathrm{RH})$, and maximum potential intensity (MPI). VWS is defined as the magnitude of the vector difference of winds between 200 and $850 \mathrm{hPa}$. The MPI is a theoretical limit for TC intensity that depends on sea surface temperature, sea level pressure, and profiles of temperature and humidity. Based on monthly 
TABLE 1. Definitions of the basins used in this study, as well as their peak seasons.

\begin{tabular}{lcl}
\hline Basin (acronym) & Geographical domain & \multicolumn{1}{c}{ Peak season } \\
\hline Western Pacific (WP) & $0^{\circ}-30^{\circ} \mathrm{N}, 100^{\circ} \mathrm{E}-180^{\circ}$ & July-October (JASO) \\
Eastern Pacific (EP) & $0^{\circ}-30^{\circ} \mathrm{N}, 180.01^{\circ} \mathrm{E}$ to American coast & July-September (JAS) \\
North Atlantic (NA) & $0^{\circ}-30^{\circ} \mathrm{N}$, American to African coast & August-October (ASO) \\
North Indian (NI) & $0^{\circ}-30^{\circ} \mathrm{N}, 40^{\circ}-100^{\circ} \mathrm{E}$ & October-December (OND) \\
South Indian (SI) & $0^{\circ}-30^{\circ} \mathrm{S}, 0^{\circ}-130^{\circ} \mathrm{E}$ & $\mathrm{January}-\mathrm{March}(\mathrm{JFM})$ \\
South Pacific (SP) & $0^{\circ}-30^{\circ} \mathrm{S}, 130.01^{\circ}-240^{\circ} \mathrm{E}$ & $\mathrm{January}-\mathrm{March}(\mathrm{JFM})$ \\
\hline
\end{tabular}

data, the MPI (Bister and Emanuel 1998) is calculated as follows, as described in Sharmila and Walsh (2017):

$$
\mathrm{MPI}=\frac{T_{s}}{T_{o}} \frac{C_{k}}{C_{D}}\left(\mathrm{CAPE}_{e}-\mathrm{CAPE}_{b}\right),
$$

where $T_{s}$ is the SST, $T_{0}$ is the mean outflow temperature, $C_{k}$ is the exchange coefficient for enthalpy, and $C_{D}$ is the drag coefficient. The quantity $\mathrm{CAPE}_{e}$ is the convective available potential energy with reference to the environmental sounding, and $\mathrm{CAPE}_{b}$ is that of boundary layer air.

To better summarize the multivariate climate controls on the simulated TC statistics, we further utilize a genesis potential index (GPI) developed by Emanuel and Nolan (2004). The GPI relates observed climate variables to observed TC formation and thus provides a means of analyzing whether the model is able to generate similar relationships, as a test of its physical fidelity. Many other alternative indices have also been developed using different predictors, however (Murakami and Wang 2010; Emanuel 2010; Tippett et al. 2011; Bruyère et al. 2012). The GPI is a statistical fit of relationship between the environmental factors and the likelihood of TC genesis, and widely adopted in several previous studies (Camargo et al. 2007b, 2010, 2014):

$$
\text { GPI }=\left(1+0.1 V_{\text {shear }}\right)^{-2}\left|10^{5} \eta\right|^{3 / 2}\left(\frac{H}{50}\right)^{3}\left(\frac{V_{\text {pot }}}{70}\right)^{3} .
$$

A general form of the Eq. (2) can be written as GPI = $\mathrm{T} 1 \times \mathrm{T} 2 \times \mathrm{T} 3 \times \mathrm{T} 4$.

Here, $V_{\text {shear }}=$ magnitude of vertical shear from 850 to $200 \mathrm{hPa}\left(\mathrm{m} \mathrm{s}^{-1}\right)$ in $\mathrm{T} 1, \eta=$ absolute vorticity at $850 \mathrm{hPa}$ $\left(\mathrm{s}^{-1}\right)$ in $\mathrm{T} 2, H=$ relative humidity at $700 \mathrm{hPa}(\%)$ in $\mathrm{T} 3$, and $V_{\text {pot }}=$ maximum potential intensity (MPI; $\mathrm{m} \mathrm{s}^{-1}$ ) in $\mathrm{T} 4$ as described above.

We also use a nonparametric statistical bootstrap method (Efron and Tibshirani 1993) to estimate the $95 \%$ confidence level of significant biases in the spatial distribution of TCG, and the two-tailed Student's $t$ test for estimating significant biases in climate conditions.

\section{Results and discussion}

\section{a. Simulated distribution of TC formation rates}

\section{1) Detected TCG Locations And Simulated ANNUAL PRECIPITATION}

As an obvious starting point to evaluate the robustness of the fine-resolution GCM, we examine the spatial distribution of the detected TCG points, along with the simulated annual-mean tropical precipitation. Figure 1 represents the model simulated geographical distributions of TCG points (red dots, Fig. 1b) compared to the observed IBTrACS data (red dots, Fig. 1a) for the period 1990-2009, overlaid with the model simulated (shaded, Fig. 1b) and GPCP (shaded, Fig. 1a) annualmean tropical precipitation. Here, the model precipitation is interpolated to the GPCP grid $\left(1^{\circ} \times 1^{\circ}\right)$ for estimating the model biases. Based on the CSIRO detection scheme, the model captures the geographic locations of TCG reasonably well compared to the observed positions. The overall positions of the simulated TCG detected match closely to those in IBTrACS. However, the model also exaggerates the simulated TCG over the Southern Hemisphere, particularly over the SP, near Madagascar in the SI, and in the South Atlantic. In contrast, the simulated TCG points are highly reduced compared with observations in the North Atlantic, and off the northwest coast of Australia. Nevertheless, this fine-resolution model simulates the global pattern of tropical precipitation quite reasonably, but it has excessive precipitation in a number of regions in the tropics, as noted by Walters et al. (2017). There are some regional differences, as the model overestimates precipitation over the WP, in the western part of equatorial Indian Ocean, and in the NA, while it underestimates over the eastern equatorial Indian Ocean and near the northwest coast of Australia. Interestingly, the geographic locations of TCG are typically at the poleward edges of the equatorial precipitation maxima in both observations and the model simulation, reflecting the typical formation of TCs within or near the poleward edge of the monsoon trough (Molinari and Vollaro 2013). 
Annual mean Precipitation \& TC genesis locations (points)

a) OBS Precip (GPCP, shaded) \& TCG locations (IBTrACS, points)

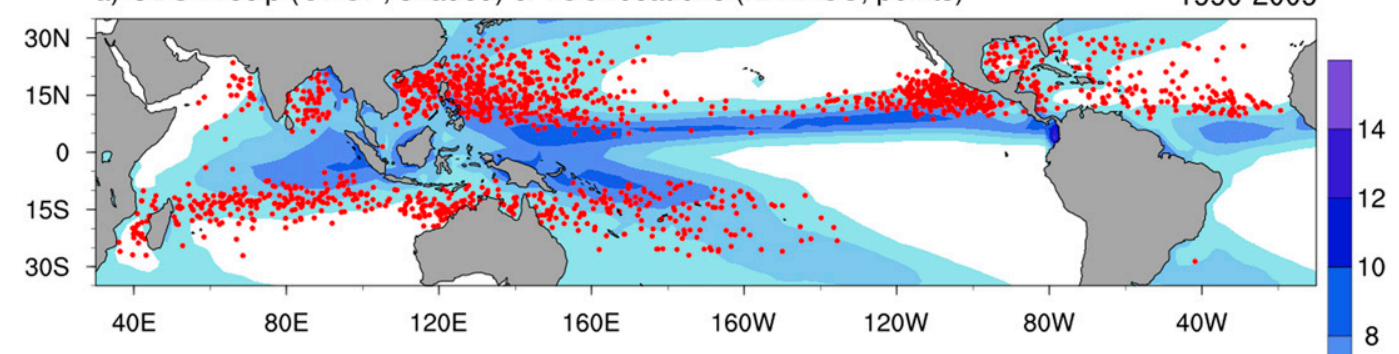

b) Model simulated Precip (shaded) \& TCG locations (points)

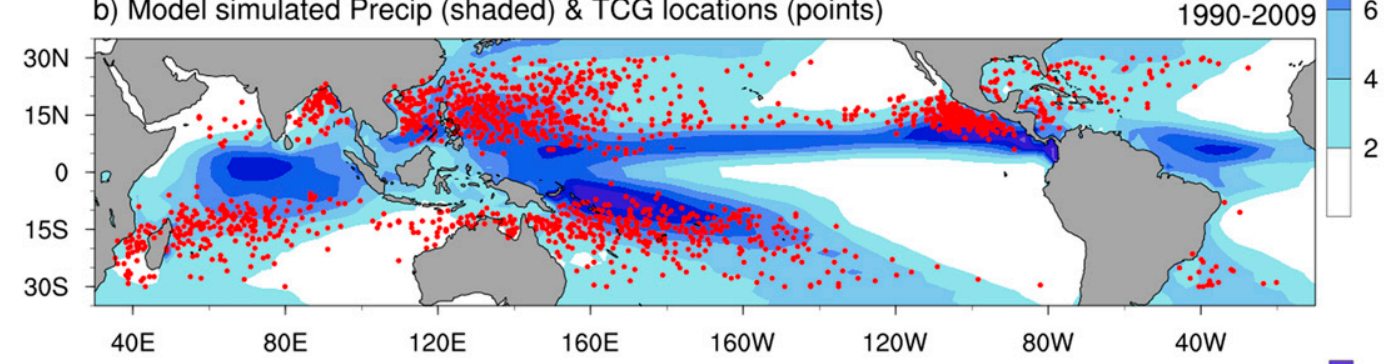

C) Model bias in Precip (Model - GPCP)

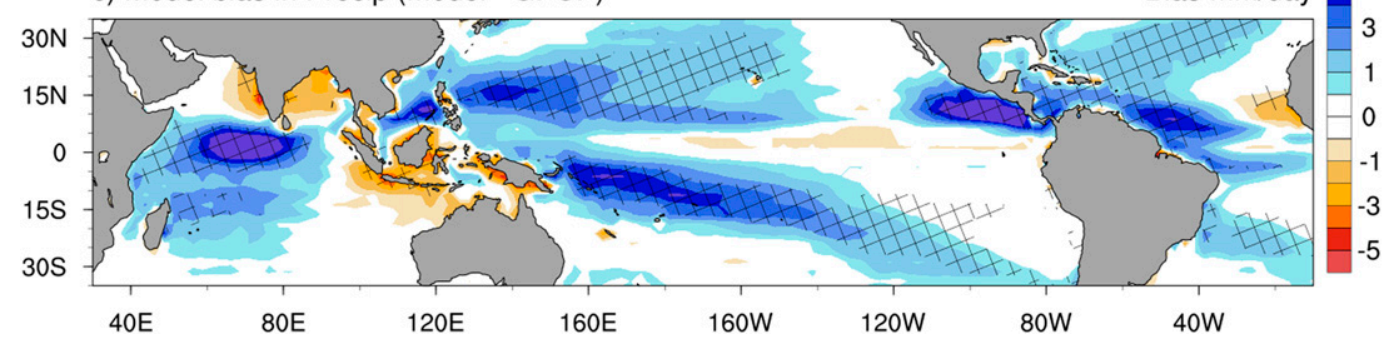

FIG. 1. Annual mean precipitation ( $\mathrm{mm} \mathrm{day}^{-1}$; shaded) over basins and the geographical locations of TCG (red dots) for (a) GPCP (shaded) and IBTrACS, and (b) model simulation for the period of 20 years (1990-2009).

(c) Model bias (shaded) in the annual mean precipitation. The values significant above the $95 \%$ confidence level in

(c) are crosshatched in black.

\section{2) TCG FREQUENCY}

The analysis of the statistics of TCG frequency gives us more detailed information on the model performance. We calculate the model simulated climatology of TC formation rates, at global and regional scales (Fig. 2). On average, about 80 TCs form every year across the globe (Emanuel 2003), and the mean number of TCs forming during the period 1990-2009 analyzed here from IBTrACS is about 80 . The TC formation rates at the regional scales vary from basin to basin depending largely on the size of the basins, and availability of TC favorable conditions. Figure 2a shows that the model well captures the observed climatology of global annual number of TCs at the $95 \%$ confidence level, but with varying interquartile ranges. At the regional scale, the model has some ability to reproduce the observed interbasin differences but there are some substantial biases in some basins (Fig. 2b); for example, the model overestimates TC formation rates in the WP and SP, while it underestimates over the NA and the SI, all significant at the $95 \%$ confidence level. The annual fractions (Fig. 2c) in each basin relative to each hemisphere, as well as the peak seasonal formation rates (Fig. 2d) across the basins (Table 1) compared to IBTrACS best track data are also shown. The model is relatively more TC active over the Southern Hemisphere, with a slightly higher percentage $(34.7 \%)$ of global TC formation compared to IBTrACS (30.6\%) for the period 1990-2009. The overall performance of the model is reasonable during the peak seasons, although the TCs are considerably fewer than observed over the NA, while there are more than observed over the SP (Fig. 2b).

\section{3) TCG ANNUAL CYCLE}

Another metric of interest is how the model simulates the annual/seasonal cycle of TC formation over individual ocean basins, which provides a measure of the 

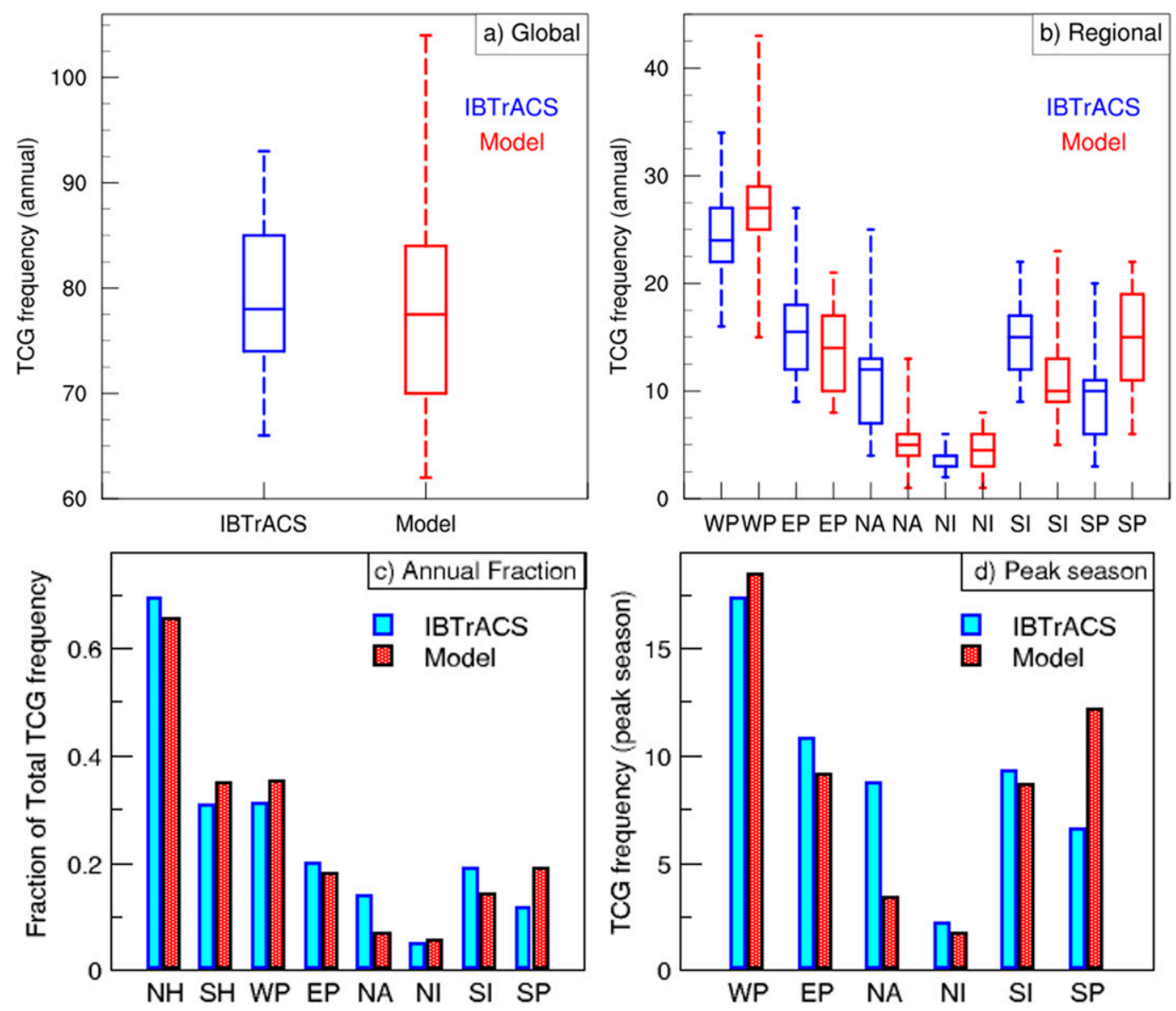

FIG. 2. Box diagrams of annual mean (a) global and (b) basin-scale TCG frequency for IBTrACS (blue) and model (red) for period 1990-2009. The horizontal line inside the boxes shows the median number of TCs per year, the top and bottom of the boxes represent the 75th and 25th percentiles, respectively, with the whiskers extending to the maximum and minimum number of TCs per year in each case. (c) The annual fraction of total TCs formed in each hemisphere (NH and $\mathrm{SH}$ ) and each basin (Table 1), and (d) average number of simulated TCs in each basin during peak seasons are also shown compared to IBTrACS.

model's TC response to variations in climate forcing at the seasonal scale. Figure 3 shows the model-simulated annual cycle of mean TC formation rates per basin (red bar) as a function of month compared to IBTrACS (blue curve). In general, the model captures the peak seasonal cycle of TCs over individual ocean basins quite realistically, despite having biases in TC formation rates in some basins (Fig. 2b). Another definite exception is the NI basin (Fig. 3f), where the model has failed to capture the observed annual cycle, which has dual peaks in the NI during the pre- and postmonsoon seasons. The bimodal annual cycle in the NI has been attributed to the annual cycle of background vertical shear as strong monsoonal shear inhibits TC formation during boreal summer. The simulation of TC-like storms in the NI during the monsoon season has been noted in several recent global models (Camargo and Wing 2016). Possible reasons may be due to the underestimated monsoonal shear and/or limitation of the detection scheme in overestimating the strength of boreal summer monsoonal low pressure systems over the NI basin (Murakami et al. 2012).

\section{4) Spatial distribution of TCG DENSity}

Next, we examine the geographic distribution of TCG density, defined as the number of TCs per $4^{\circ} \times 4^{\circ}$ grid box per year or peak season. Figure 4 shows the observed (Fig. 4a) and the simulated (Fig. 4b) annual TCG density and the model biases (model minus observation; Fig. 4c). The model reproduces the spatial distribution of the annual TCG density reasonably well, but with some key differences. The most noticeable difference is the highly underestimated TCG density in the main development region $\left(10^{\circ}-20^{\circ} \mathrm{N}, 60^{\circ}-15^{\circ} \mathrm{W}\right)$ over the NA basin, a common issue noted in the majority of recent climate models (Shaevitz et al. 2014). Inherent modest 


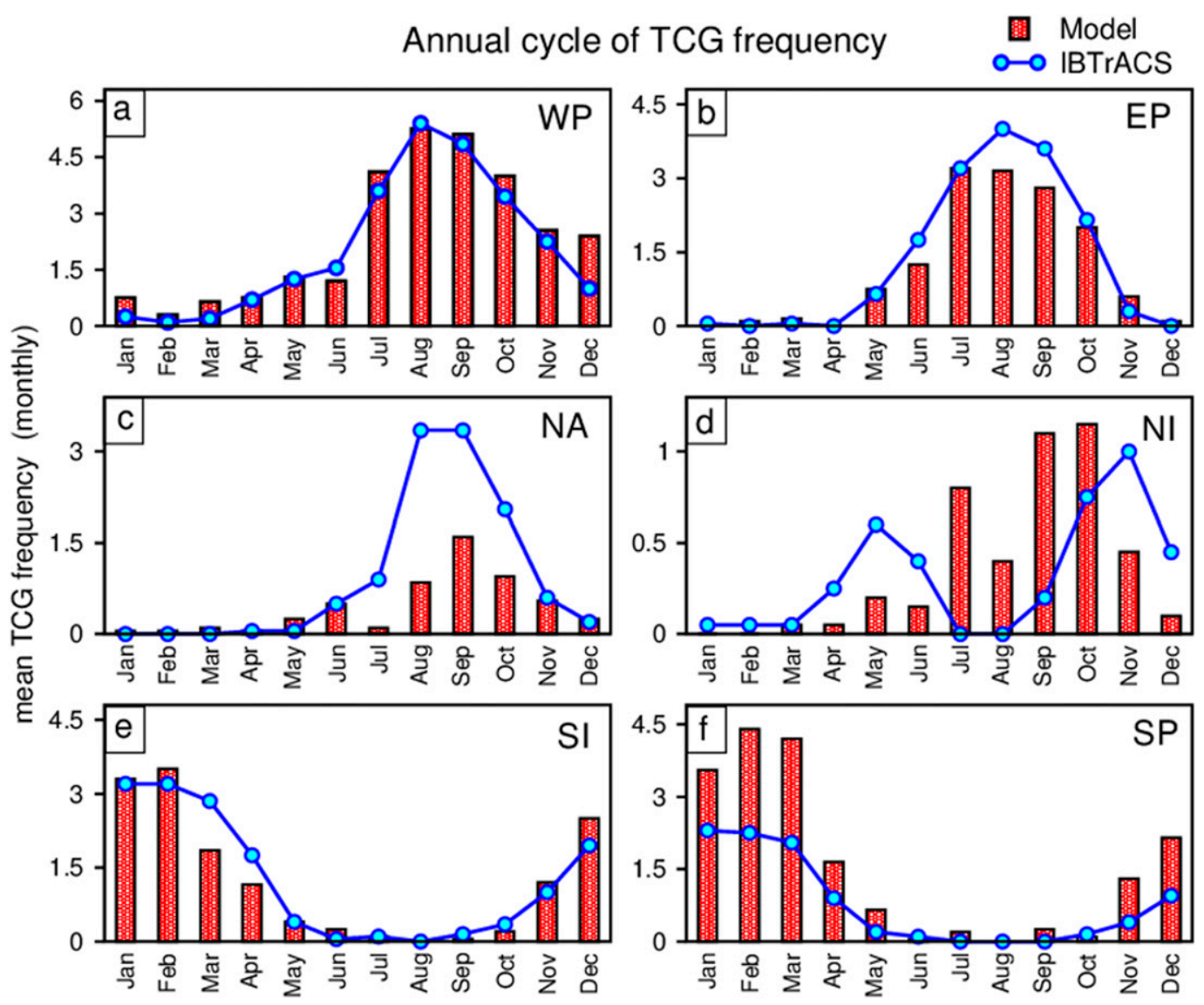

FIG. 3. Annual cycle of mean tropical cyclones per month and per basin for model simulations (red bars) compared to observations (blue curve).

model biases can easily lead to a reduction of the TC activity in that region. Other differences include underactive TC formation in the EP that appears to have insufficient westward extension of the main region of observed formation, and in the eastern half of the SI in the region close to the northwest coast of Australia. In addition, the model overestimates TCG density in the central-to-northeast region of the WP, north of the Bay of Bengal in the NI, over the western half of the SI, and in the SP, where a general overestimation of formation is observed along with an extended TCG region farther east compared to the observations.

\section{5) BASIN-WISE TCG DENSITY DURING PEAK SEASONS}

We also estimate how the model captures the basinwise seasonal patterns of TCG density for the individual basin peak TC seasons (Fig. 5). The overall basin-wise TCG densities are moderately well simulated during peak TC seasons (Figs. 5g-1) compared to observation (Figs. 5a-f), and the differences (Figs. 5m-r) in the basin-to-basin regional patterns during peak TC seasons are quite comparable to the biases noted in the simulated annual TCG density. However, a few more regional differences are also noticed during peak TC seasons, such as the lower TCG density prominent in the WP (around $120^{\circ}-150^{\circ} \mathrm{E}$ ) (Fig. $5 \mathrm{~m}$ ), and also in the Bay of Bengal, that appear to be linked with the poorly simulated seasonal cycle of TCG in the NI basin (Fig. 5p). The identified TCG biases could potentially be caused partly by the inadequate representation of the TC-favorable seasonal large-scale climatic conditions.

\section{b. Interannual variability of TCG}

Since this is an AMIP-style simulation, we assess the ability of the model to simulate the interannual variability of TC formation rates. Figure 6 shows the simulated global number of TCG per year for the model (red bars) compared to IBTrACS (blue bars), as well as for the individual basins separately. To quantify the ability of the model to reproduce the interannual variability of observed TCs in individual basins, we calculate the correlation coefficient between the model-simulated and observed TCG per year in each basin. The correlation is 


\section{Simulation of TC genesis density}

a) IBTrACS

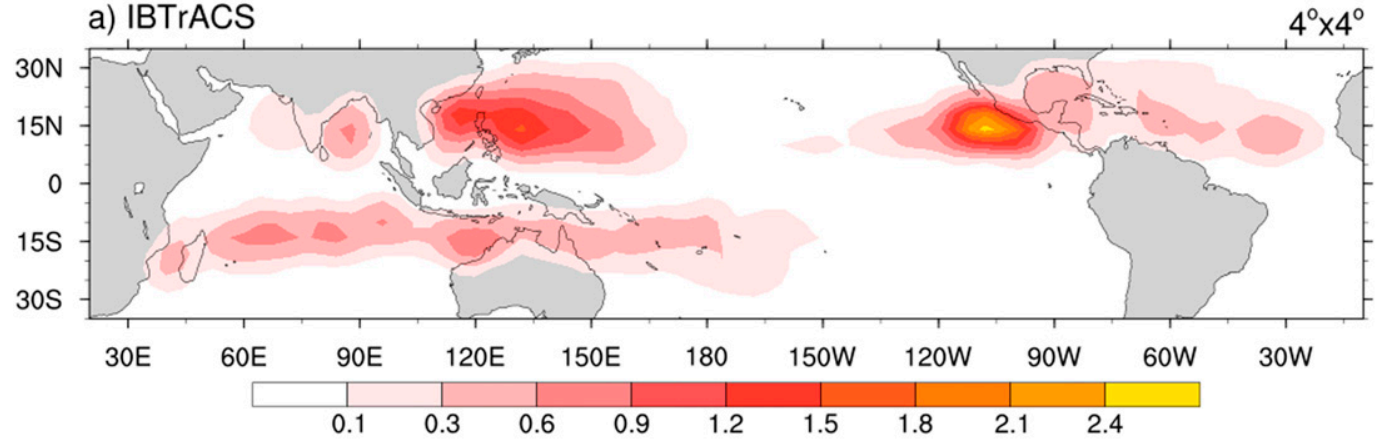

b) Model

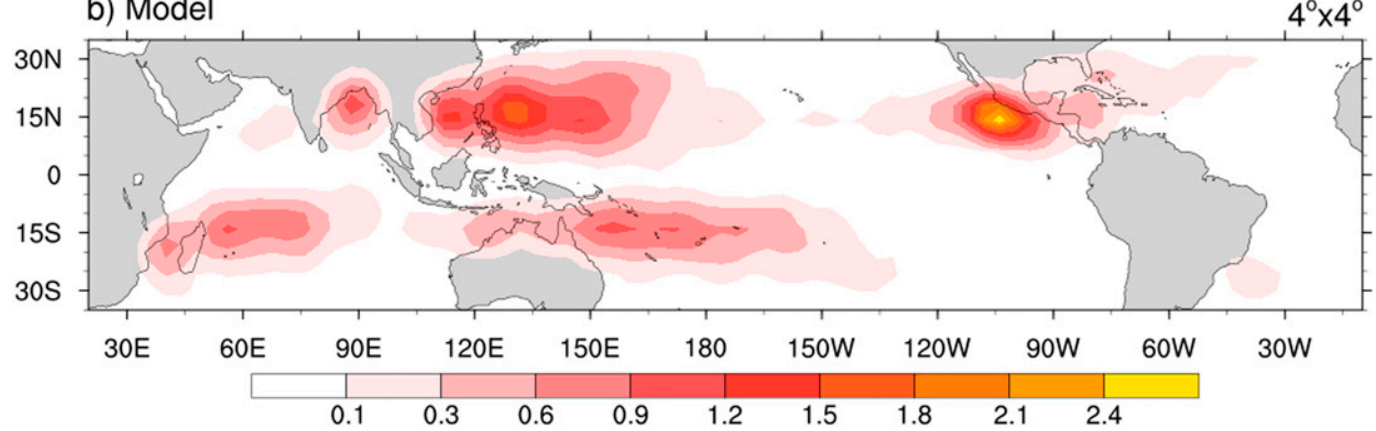

c) Bias: (Model - IBTrACS)

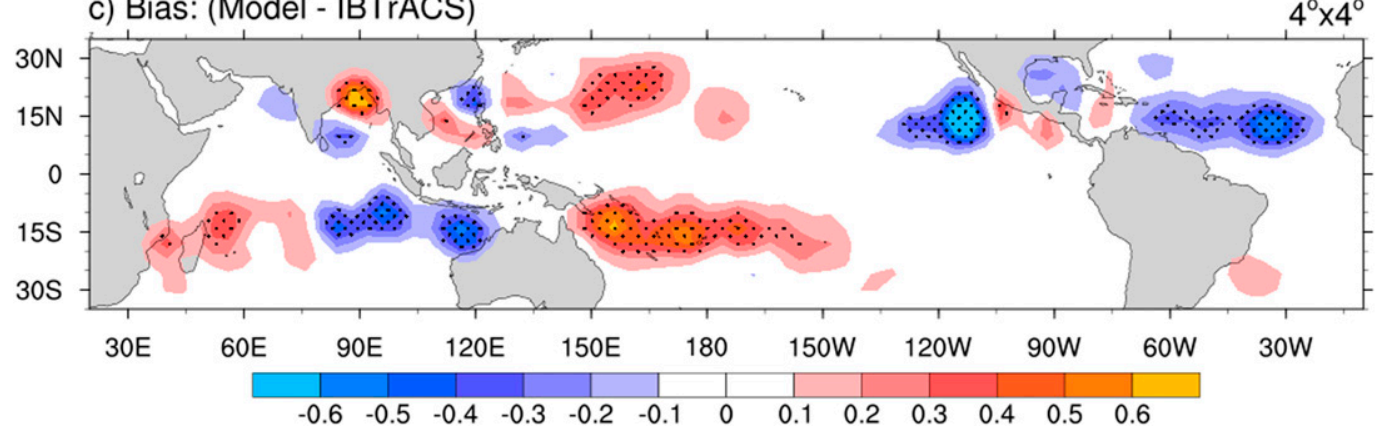

FIG. 4. Annual mean TC genesis density $\left(\times 10^{-1}\right)$ per $4^{\circ} \times 4^{\circ}$ grid box in each basin for the period 1990-2009 for (a) IBTrACS, (b) model simulation, and (c) model bias (model minus IBTrACS). The values significant above the $95 \%$ confidence level are stippled using a bootstrap method.

high and significant at the $95 \%$ confidence level only in the NA and EP basins, mostly driven by the dominant mode of tropical climate variability, El Niño-Southern Oscillation (ENSO), which significantly affects the spatial distribution and the statistics of TCs (e.g., Camargo et al. 2010). Although the simulated global number of TCs in this model is comparable to the observed number, the global interannual variability is not well captured in this model. Note that the relationship between ENSO and TC formation differs in polarity between some of the basins, and this cancellation effect probably explains the low correlation between observed and simulated global TC numbers. Similarly, the SP basin has two regions of opposite ENSO polarity within it, divided by the $170^{\circ} \mathrm{E}$ meridian (e.g., Basher and Zheng 1995), so the low correlation there is not surprising either (Shaevitz et al. 2014).

We further assess how the model captures the ENSOdriven influence on the regional TCG locations and frequency for the period 1990-2009. The annual TCG density composites for the El Niño and La Niña years are computed separately for the Northern and Southern Hemispheres. We use an standard ENSO index (the oceanic Niño index from the Climate Prediction Center, available at http://www.cpc.ncep.noaa.gov/products/ analysis_monitoring/ensostuff/ensoyears.shtml) to identify the El Niño and La Niña seasons where the Northern (Southern) Hemisphere season definitions are based on 

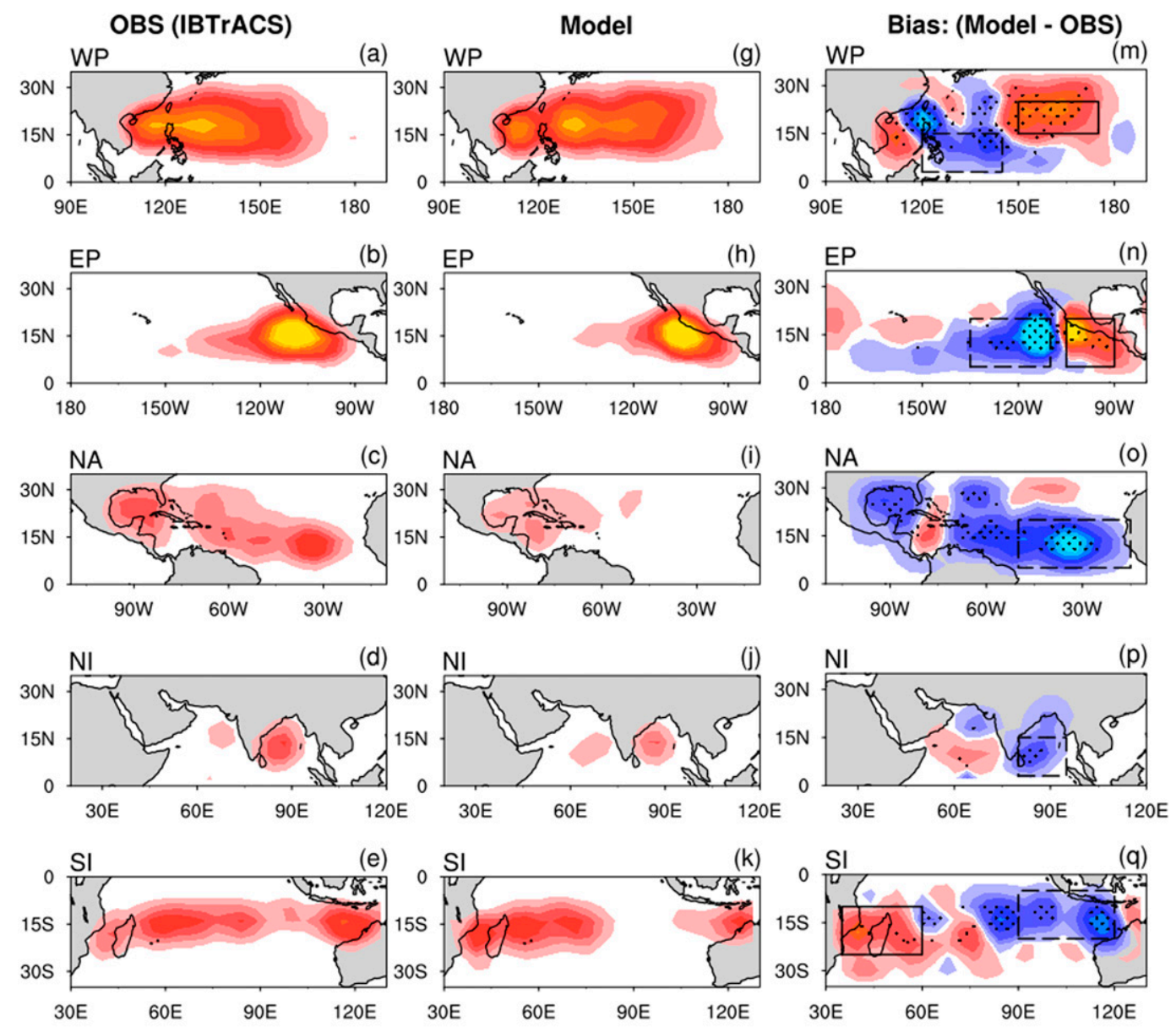

(k)
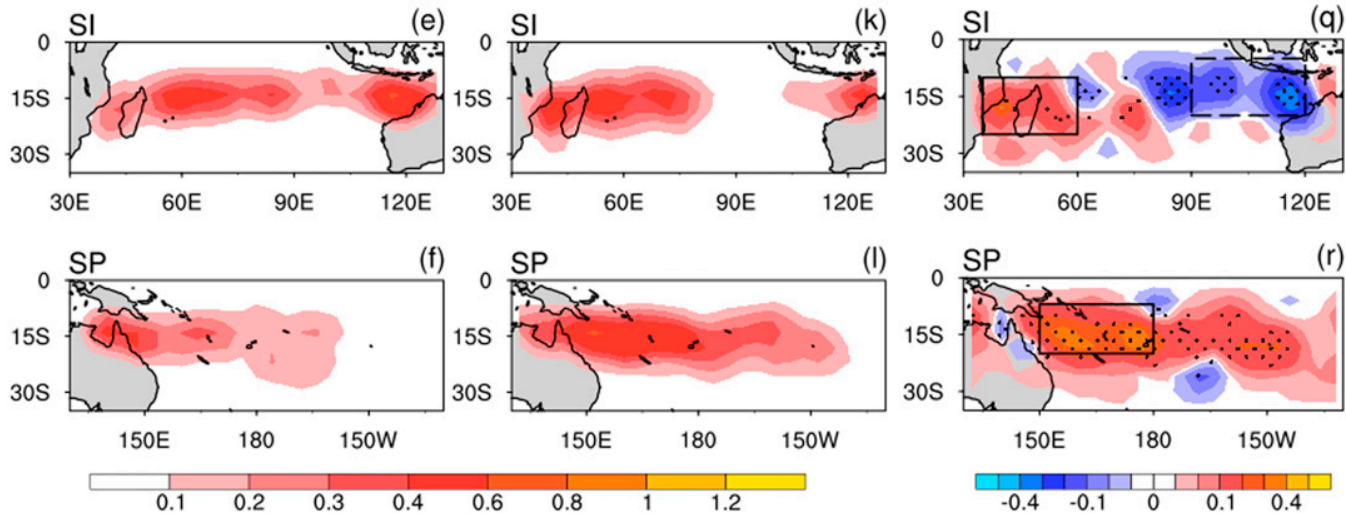

FIG. 5. Regional TC genesis density $\left(\times 10^{-1}\right)$ per $4^{\circ} \times 4^{\circ}$ grid box per peak season for individual ocean basins for (a)-(f) IBTrACS and (g)-(l) model, and (m)-(r) corresponding model biases (model minus IBTrACS) over each basin, for the period 1990-2009. The regions selected as the regions of positive (negative) biases are shown in solid (dashed) boxes. The values significant above the $95 \%$ confidence level are stippled using a bootstrap method.

the state of ENSO in the August-October (JanuaryMarch) seasons, where the Southern Hemisphere seasons are defined from July to June, encompassing parts of two calendar years (Table 2). The observed and the simulated TCG density difference between El Niño and La Niña years over the period 1990-2009 are shown in Fig. 7. The IBTrACS data (Fig. 7a) show the well-known ENSOdriven influences on TCs, such as the increased and southeast shift of TCs toward the date line in the WP (Wang and Chan 2002; Camargo et al. 2007a), a southwest shift in the EP (Chia and Ropelewski 2002), and suppressed TC activity in both the NA (Kossin et al. 2010) and in the Bay of Bengal (Felton et al. 2013) during El Niño years. In the Southern Hemisphere, reduced TCG to the west of Australia and enhanced TCG in both the western part of SI and closer to the east coast of Africa, and also the southeastern part of SP, is observed during El Niño years (Kuleshov et al. 2008). It is evident that the model can realistically capture the spatial patterns of the observed difference in TCG density between El Niño and La Niña conditions in most TC basins (Fig. 7b), in reasonable agreement with the observations. 


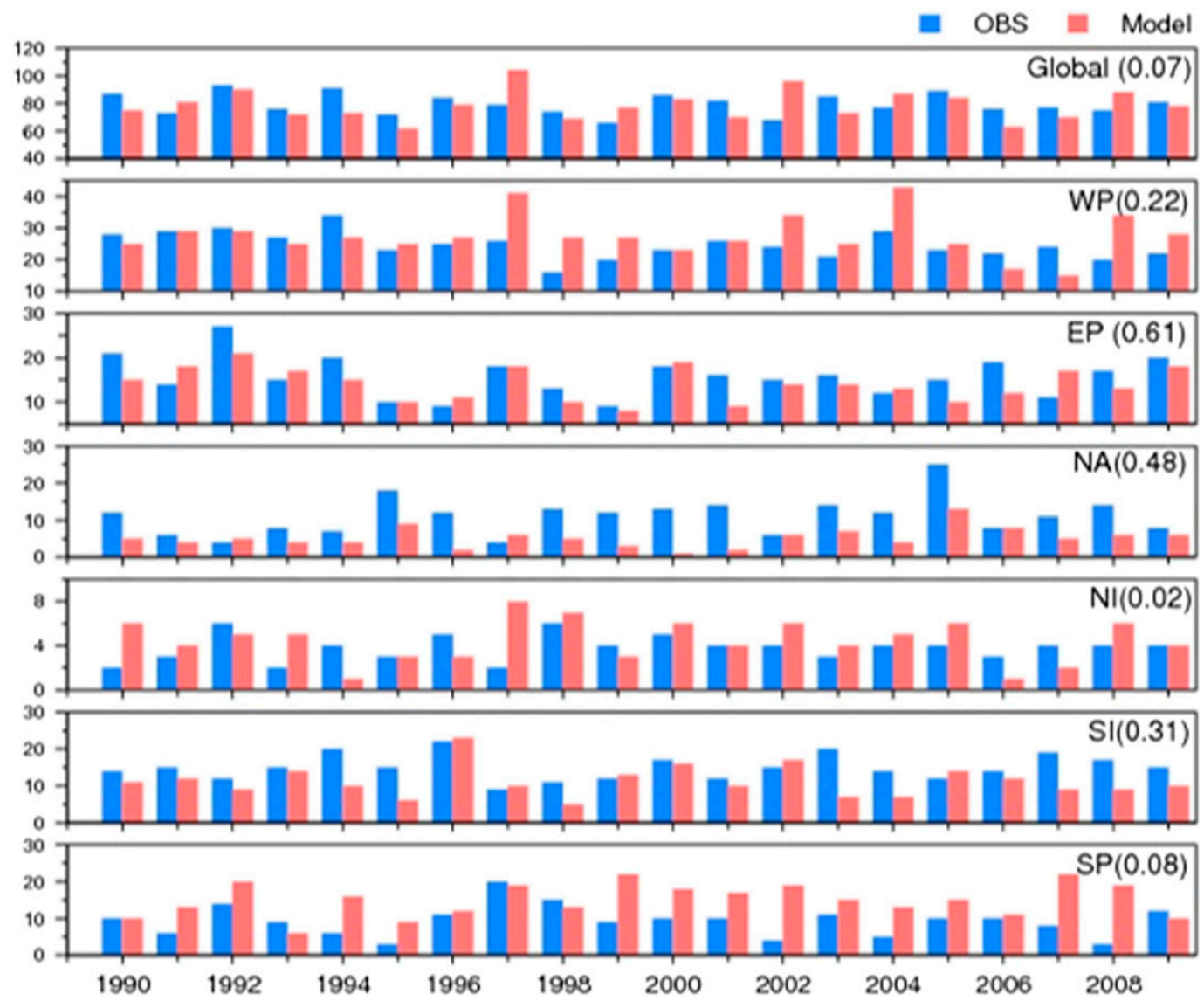

FIG. 6. Simulated interannual variability of TC formation rates (number of TCs per year): IBTrACS (blue) and model (red) for global and individual ocean basins. The correlation between model-simulated and observed TC formation rates is shown in parentheses. The correlation values of EP and NA are statistically significant at the $95 \%$ confidence level.

An exception is in the NA basin where TCs are poorly detected compared to the observed TCG density, a common issue in many recent climate models (e.g., Walsh et al. 2016). Consistent with the above discussion, the model also could not reproduce the enhanced TCG in the western SI as evident in the observations, especially over the area from $40^{\circ}$ to $80^{\circ} \mathrm{E}$. To examine the possible causes of the model biases in TC formation rates, in the next subsection we assess the ability of the model in simulating the large-scale tropical climate conditions that influence the TC formation rates.

\section{c. Influence of simulated tropical climate conditions}

The number of TCs that form each year and in each basin depends largely on the specific large-scale tropical environment (e.g., Sharmila and Walsh 2017). Thus, a systematic evaluation of the model's performance in simulating climate conditions that are crucial for TC formation is essential, focused primarily during the TC-active seasons. Any systematic model biases in the large-scale patterns of TC-favorable dynamical and thermodynamical conditions can influence the realistic simulation of TCG climatology. As an initial step, we use a Taylor diagram (Taylor 2001) to demonstrate the model's overall fidelity in simulating the

TABLE 2. El Niño and La Niña years for Northern (Southern) Hemispheres based on warm and cold ENSO states in the ASO (JFM) seasons of Climate Prediction Center. (Note that here the annual TCG density over the Southern Hemisphere is calculated from July to June, encompassing two calendar years.)

\begin{tabular}{lcccc}
\hline \hline \multicolumn{2}{c}{ Northern Hemisphere } & & \multicolumn{2}{c}{ Southern Hemisphere } \\
\cline { 5 - 5 } El Niño & La Niñan & & El Niño & La Niña \\
\hline 1991 & 1995 & & $1991 / 92$ & $1995 / 96$ \\
1994 & 1998 & & $1994 / 95$ & $1998 / 99$ \\
1997 & 1999 & & $1997 / 98$ & $1999 / 2000$ \\
2002 & 2000 & $2002 / 03$ & $2000 / 01$ \\
2004 & 2007 & & $2005 / 06$ \\
2006 & & & \\
2009 & & & \\
\hline
\end{tabular}




\section{Simulation of TC genesis (ENSO period)}

a) OBS (EI Niño - La Niña)

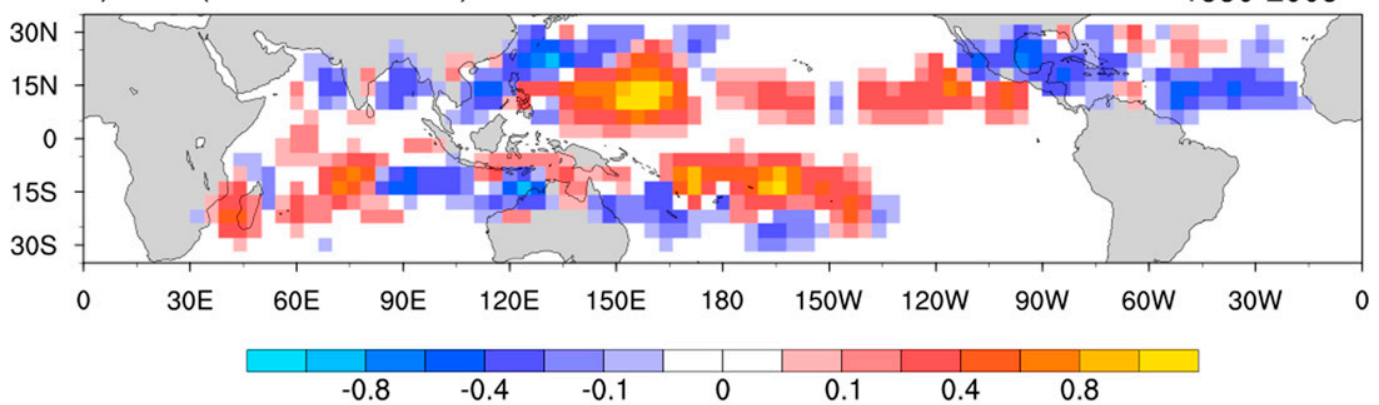

b) Model (El Niño - La Niña)

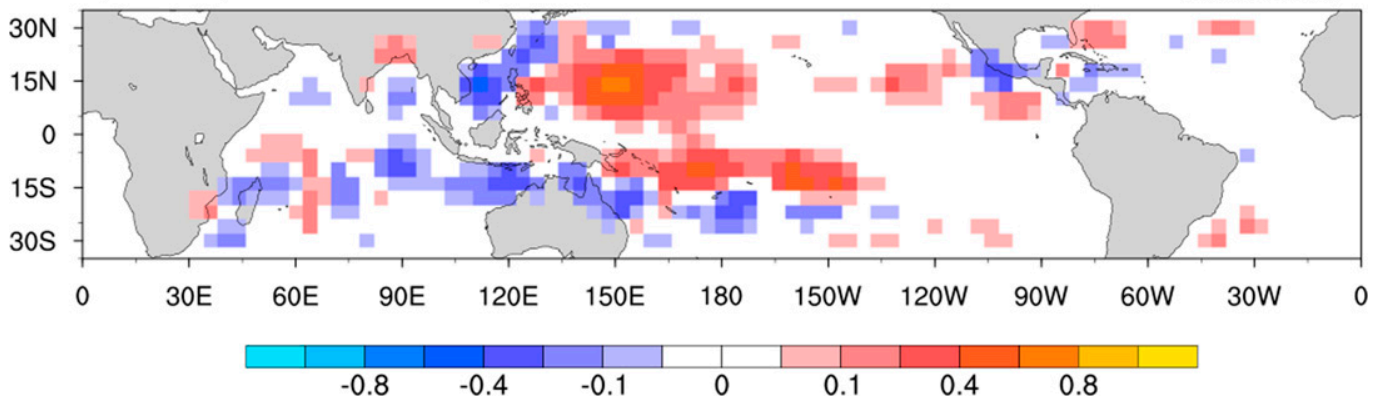

FIG. 7. Differences in annual TC genesis density $\left(\times 10^{-1}\right)$ per $4^{\circ} \times 4^{\circ}$ grid box between El Niño and La Niña periods for (a) observation and (b) model. Here, TCG density difference in the Southern Hemisphere is calculated from July to June, encompassing parts of two calendar years.

seasonal-mean large-scale climate (such as precipitation, low- and high-level winds, vertical shear, midlevel relative humidity, ascending motion, etc., along with MPI and GPI) during boreal summer (JAS) and austral summer (JFM), which covers most of the TC peak seasons over the tropics $\left(30^{\circ} \mathrm{S}-30^{\circ} \mathrm{N}\right)$ in terms of their spatial pattern correlation, root-mean-square difference, and the ratio of variances compared to observation (Fig. 8). The diagram reveals that the model reasonably captures the overall spatial patterns of tropical large-scale climate variables, although it performs slightly better during JFM. However, the model also produces larger variance for most of the variables compared to the observations. We noted earlier that precipitation is one of the worst simulated variables here, as expected.

Although the overall patterns of large-scale climate variables are quite reasonably captured over the tropical domain, it is also important to examine the basin-wise model performance. We selected four climate variables (dynamical: vertical wind shear and relative vorticity at $850 \mathrm{hPa}$; and thermodynamical: relative humidity at $700 \mathrm{hPa}$ and MPI) crucial for TC formation rates [following Sharmila and Walsh (2017)] and compared the basin-specific peak-TC seasonal model climatology with the observed climatology. These variables have been regularly utilized in the various previous genesis indices (Camargo et al. 2007b; Camargo and Wing 2016). The identified systematic regional biases in relevant climate variables are shown in Fig. 9.

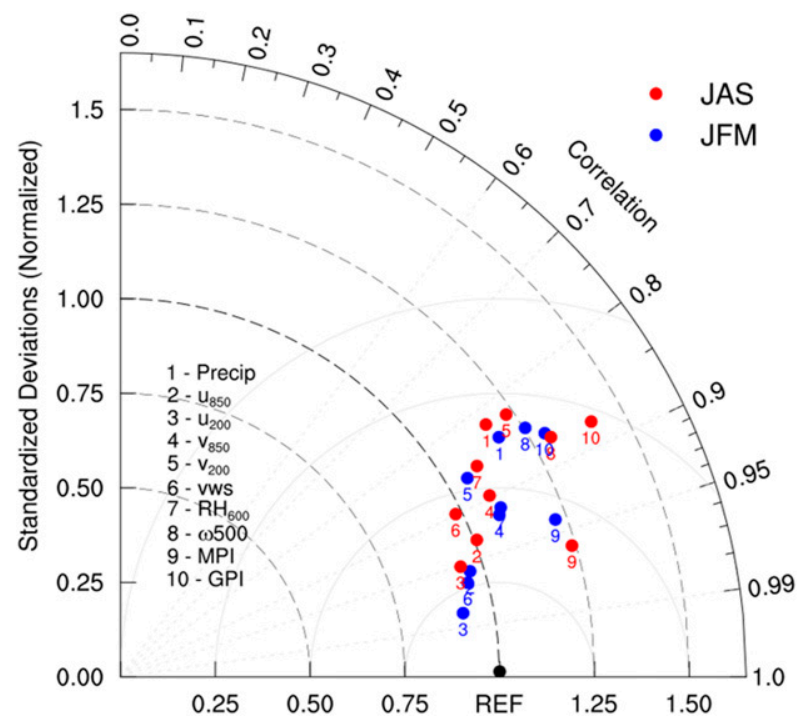

FIG. 8. Taylor diagram showing the performance of the model in simulating large-scale climate variables over the tropics $\left(30^{\circ} \mathrm{N}-30^{\circ} \mathrm{S}\right)$ for boreal summer (red dots) and winter (blue dots). 
I. Western Pacific region
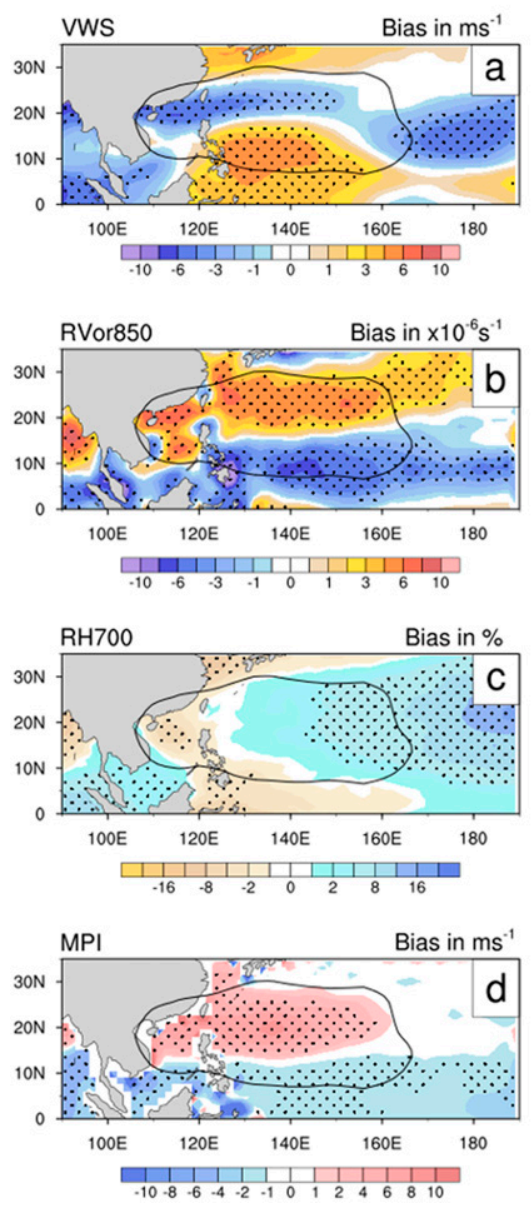

II. East Pacific region
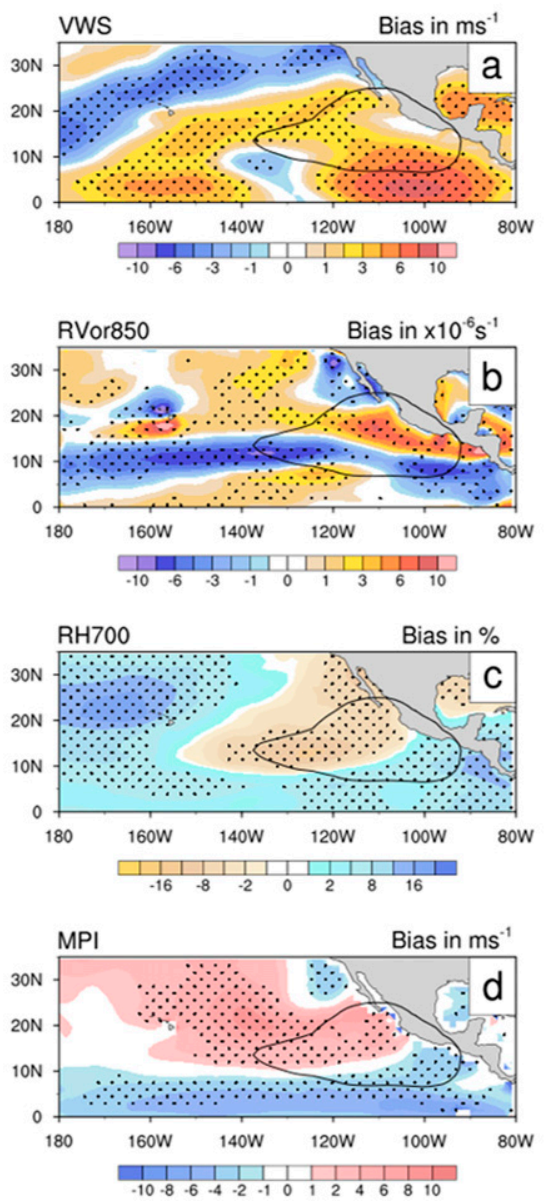

\section{North Atlantic region}
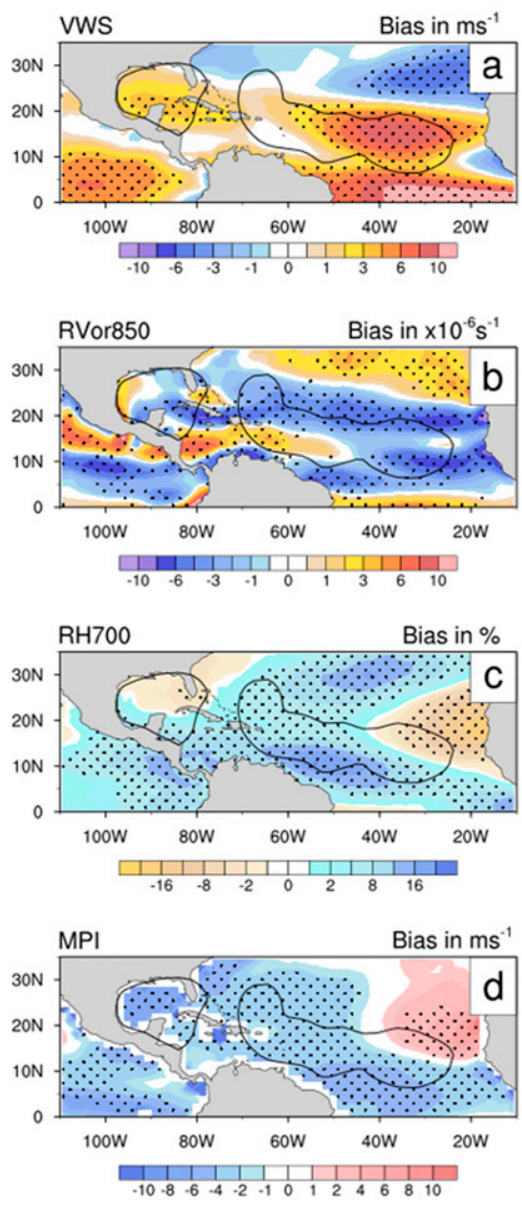

FIG. 9 Regional biases (model minus reanalyses) in climate conditions over the (I)-(III) NH basins (WP, EP, NA) during peak TC seasons, for (a) vertical wind shear (VWS), (b) relative vorticity at $850 \mathrm{hPa}$ (RVor850), (c) relative humidity at $700 \mathrm{hPa}$ (RH700), and (d) maximum potential intensity (MPI). The values significant above the $95 \%$ confidence level are stippled using the Student's $t$ test. The observed TCG main development region over each individual basin is shown using a $0.2 \times 10^{-1}$ black contour.

\section{1) Model biases in Dynamical CONDitions}

Weak vertical wind shear and strong low-level cyclonic vorticity are considered as favorable conditions for TCG frequency. Thus, any substantial inherent model bias in those conditions could influence the simulated TC formation rates and may partly explain the TCG biases. In the WP basin (Fig. 9Ia), the model has positive shear bias in the deep tropics $\left(0^{\circ}-15^{\circ} \mathrm{N}\right)$ and negative bias poleward of $20^{\circ} \mathrm{N}$ up to $30^{\circ} \mathrm{N}$. Concomitant bias in the low-level relative vorticity but of opposite sign (Fig. 9Ib) is also present, which could influence the estimated TC formation rates in this region (Fig. 3). The model further simulates stronger wind shear over the entire EP (Fig. 9IIa), the NA (Fig. 9IIIa), and the NI (Fig. 9IVa), which tend to simulate low TC formation rates (Fig. 5). In the EP, a possible connection between the bias in vorticity and TCG bias is a little ambiguous, although positive wind shear bias southwest of the Baja Peninsula appears to be inhibiting the extension of simulated TC formation as far west as observed. In the NA region, the suppression of cyclonic vorticity would tend to suppress TCG, and thus could act to amplify the suppressive effect of the positive wind shear bias on TCG. Both the positive shear bias and the negative relative vorticity bias in the main development region of NA might help to explain the highly reduced simulated TC formation rates over that region (Fig. 5o). Over the Southern Hemisphere, the model produces a highly cyclonic vorticity bias from the eastern Australian coast to the east of the date line in the TC development region, 
IV. North Indian region
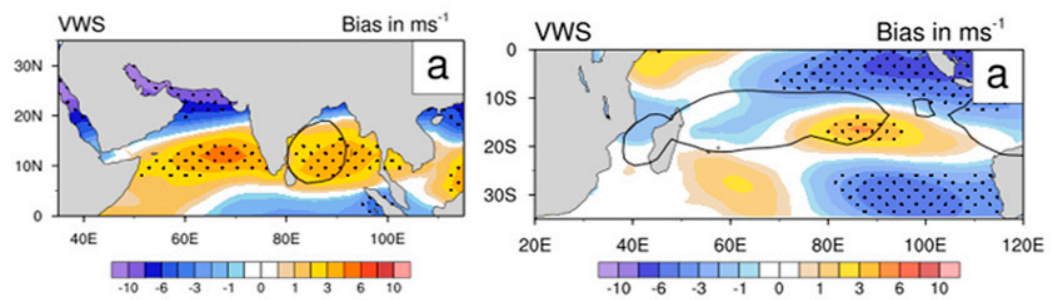

V. South Indian region
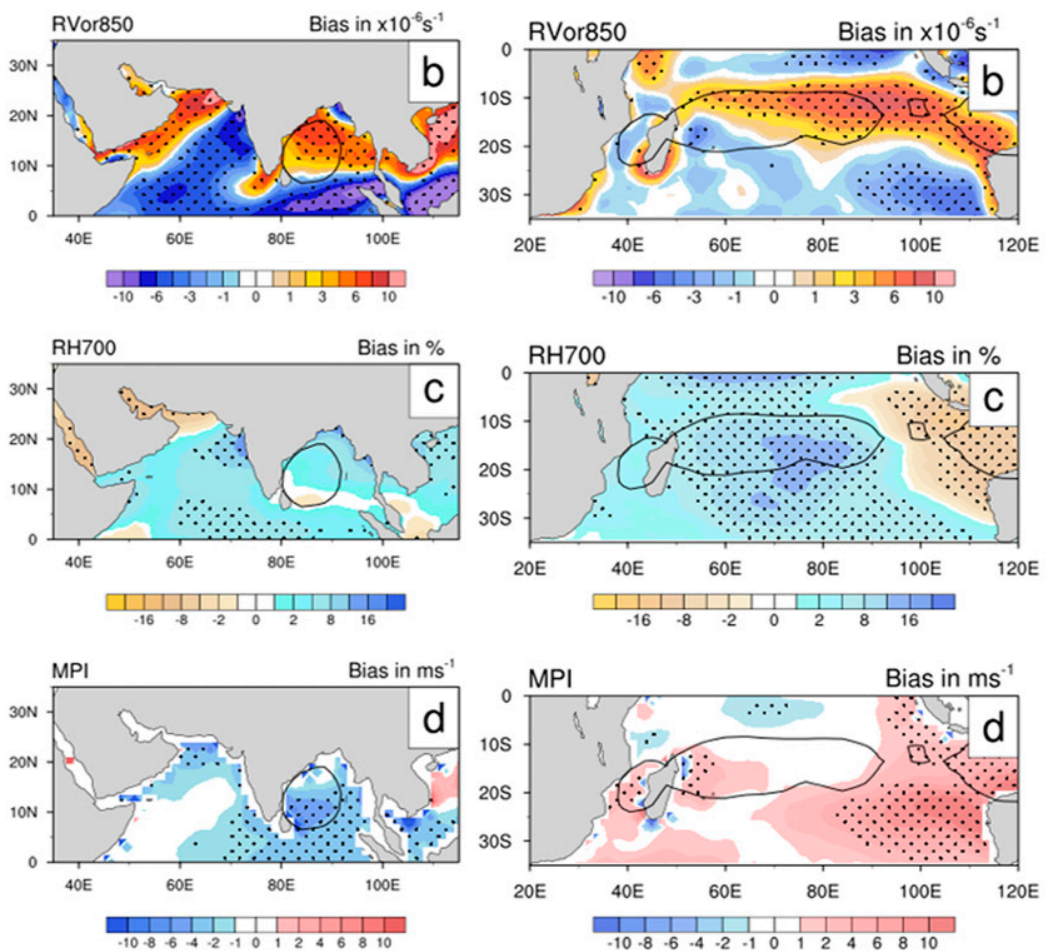

\section{South Pacific region}
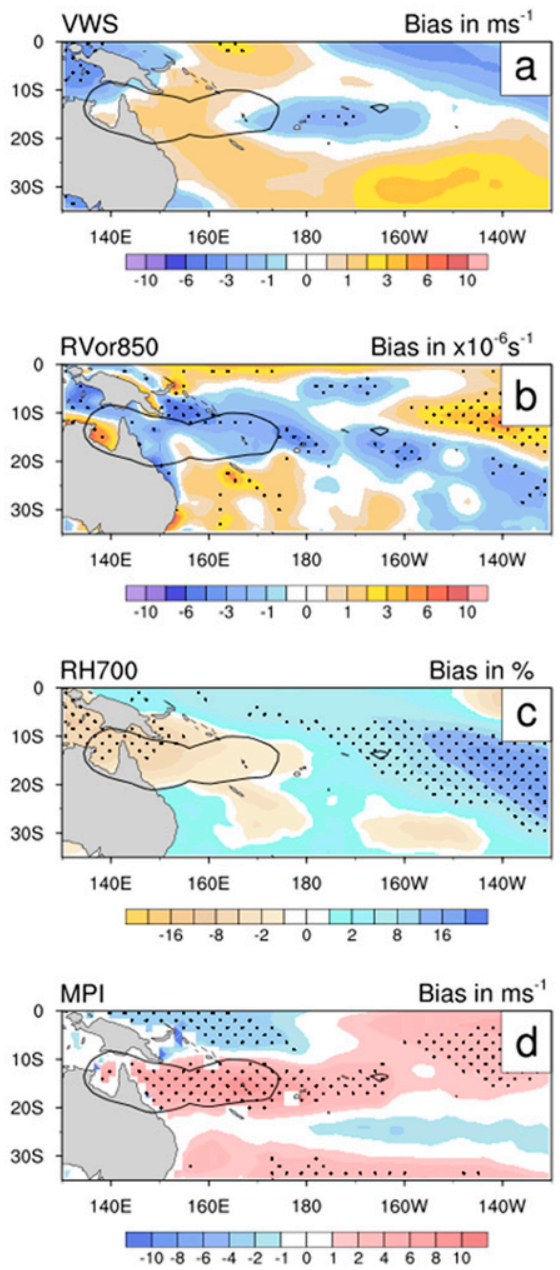

FIG. 9 IV-VI. As in (I)-(III), but for the NI and for the SH basins (SI and SP).

concomitant with overestimated TCs in the SP, while weaker shear east of $170^{\circ} \mathrm{E}$ and modest positive biases in wind shear off the coast of Queensland are also noted. In the SI basin, the reduced TCG near the northwest coast of Australia is well collocated with the large anticyclonic vorticity bias (Fig. 9Vb), and slightly positive shear in the TCG region of the SI basin (Fig. 9V), while the positive TCG bias in the west is partly associated with the accompanying bias in the dynamical conditions.

\section{2) MODEL BIASES IN THERMODYNAMICAL CONDITIONS}

In general, the model mostly has a large positive bias in the relative humidity during the peak TC seasons of individual basins (Fig. 9c). For example, the model overestimates the relative humidity in the entire WP, except near the equatorial warm pool region (Fig. 9Ic).
In contrast, the relative humidity is highly underestimated over the main TC development region in the EP except east of $100^{\circ} \mathrm{W}$ (Fig. 9IIc). Interestingly, in the NA, the simulated relative humidity shows considerable positive bias in the TC inactive regions, although a large plume of drier-than-observed air is also evident near the African coast (Fig. 9IIIc). Similarly, the positive humidity bias in the NI has no clear association with the negative TCG bias (Fig. 9IVc), suggesting that the negative TCG bias is mainly owing to the biases in the dynamical conditions (Fig. 9IVa). Turning to the Southern Hemisphere basins, the model consistently overestimates the relative humidity in the SI (Fig. 9Vc), although a considerable dry zone near the warm pool and northwest coast of Australia are also evident, suggesting a clear association with the negative TCG bias in that region. However, a similar dry zone near the east coast of Australia is noted 


\section{Basin-wise model bias in GPI}
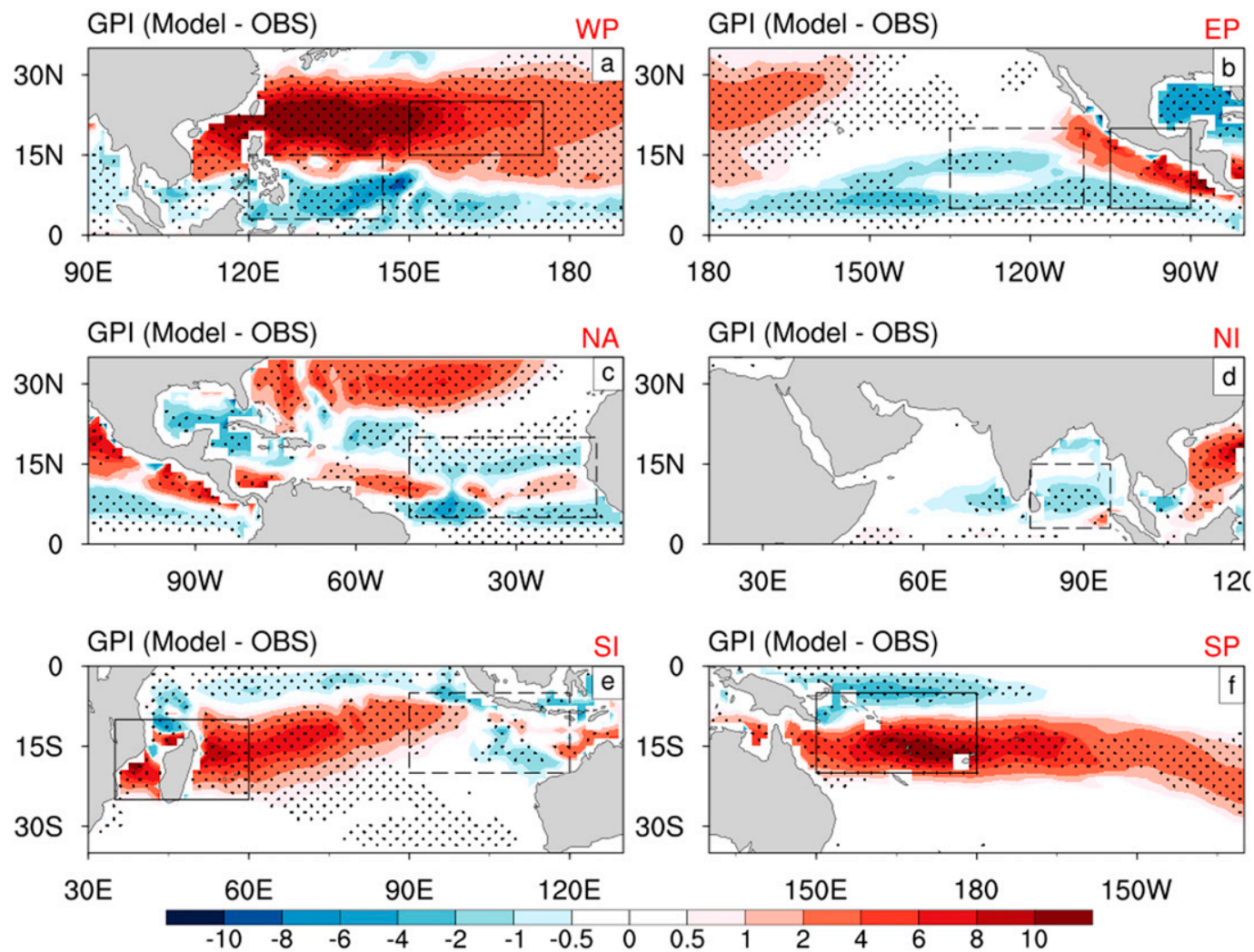

FIG. 10. Model bias (model minus reanalysis) in regional GPI for individual basins during peak TC seasons. Here, the regional boxes of positive (solid line) and negative (dashed line) TCG are also displayed (Table 3). The values significant above the $95 \%$ confidence level are stippled using the Student's $t$ test.

in the SP, suggesting its inconsistent association with the positive TCG bias in this region (Fig. 9VIc). We also note that there is no systematic association between the local MPI biases and the TCG biases (Fig. 9d) except over the NA. In summary, while there appears to be some relationship between regions of relative humidity bias and biases in TCG, this relationship is not entirely consistent.

\section{3) GPI SIMULATION}

We compute the model GPI climatology for peak TC seasons of individual basins (see section 2c) and compare with reanalysis GPI climatology. The model can reasonably capture the spatial pattern, the well-known TC active regions with respect to GPI maxima compared to the reanalysis GPI (figure not shown). The model generally overestimated the magnitude in most basins, however (Fig. 10). It shows that the simulated regional GPI biases are not necessarily consistent with all regional TCG biases. For instance, the model shows highly positive GPI bias north of $20^{\circ} \mathrm{N}$ in the NA but has highly reduced TC activity.

To investigate the competing influence of large-scale climate factors contributing to the biases in the simulated GPI, and to relate the corresponding biases in the simulated TCG, we select a few specific boxes (Table 3 ) in the individual basins, over which the model shows notable positive (solid box) or negative (dashed box) biases in TCG density (Fig. 5) during the peak TC seasons. Then we compute the box-averaged GPI, and each of the four contributing terms corresponding to the region-dependent biases in TCG (see Fig. S1 in the online supplemental material). We calculated the relative error of simulated GPI along with each four components [following Camargo et al. (2007)] compared to the GPI and all four terms from reanalysis. The relative error is defined as the difference between the model climatology and the reanalysis climatology normalized by the magnitude of the reanalysis climatology. Although the net relative error in GPI cannot be described as the sum of the contributions from the four factors due to its 
TABLE 3. The regional domain for calculating area-averaged relative error in each term of GPI.

\begin{tabular}{ccc}
\hline \hline Basin (sign of TCG bias) & Sign of GPI bias & Geographical domain (lat, lon) \\
\hline WP (+) & + & $15^{\circ}-25^{\circ} \mathrm{N}, 150^{\circ}-175^{\circ} \mathrm{E}$ \\
WP (-) & - & $3^{\circ}-15^{\circ} \mathrm{N}, 120^{\circ}-145^{\circ} \mathrm{E}$ \\
EP (+) & + & $5^{\circ}-20^{\circ} \mathrm{N}, 255^{\circ}-275^{\circ} \mathrm{E}$ \\
EP (-) & - & $5^{\circ}-20^{\circ} \mathrm{N}, 225^{\circ}-250^{\circ} \mathrm{E}$ \\
NA (-) & - & $5^{\circ}-20^{\circ} \mathrm{N}, 310^{\circ}-345^{\circ} \mathrm{E}$ \\
NI (-) & + & $3^{\circ}-15^{\circ} \mathrm{N}, 80^{\circ}-95^{\circ} \mathrm{E}$ \\
SI (+) & + & $10^{\circ}-25^{\circ} \mathrm{S}, 35^{\circ}-60^{\circ} \mathrm{E}$ \\
SI (-) & + & $5^{\circ}-20^{\circ} \mathrm{S}, 90^{\circ}-120^{\circ} \mathrm{E}$ \\
SP (+) & $5^{\circ}-20^{\circ} \mathrm{S}, 150^{\circ} \mathrm{E}-180^{\circ}$ \\
\hline
\end{tabular}

nonlinearity, it can provide an adequate quantification of the role of each of the different factors. The estimates of box-averaged relative errors for each component along with GPI corresponding to the positive and negative TCG biases (red dots, right $y$ axis) over the individual basins (Fig. 5) are shown in Fig. 11. The boxaveraged relative error in the GPI (gray bar), and all four contributing terms in Eq. (2), namely T1 (vertical wind shear; blue bar), T2 (absolute vorticity; maroon bar), T3 (relative humidity; green bar), and T4 (maximum potential intensity; orange bar), are shown in Fig. 11. The figure shows that the estimated relative error in GPI is consistent with the sign of TCG biases in most of the selected locations (Table 3), but with some differences. Note that the GPI is inversely proportional to the square of vertical shear, so the positive contribution of the GPI means lower shear. In the WP, the sign of TCG biases matches with the estimated relative error in the GPI; for example, for the positive bias in GPI, all terms except T4 (related to MPI) contributed positively, although relative humidity is the dominant one among them. In contrast, in the region of the WP with a negative bias, the negative contribution from dynamical terms plays the dominant role, consistent with the stronger shear and negative vorticity bias identified in this region (Figs. 9Ia,b and Fig. S2). The stronger shear in the region east of the Philippines is likely caused by a substantial positive anomaly in convection simulated in the equatorial Indian Ocean, which could lead to increased shear in the western part of the WP basin due to associated increased upper-level outflow over the Indian Ocean and resulting increased westerlies to the east of the convective anomaly, similar to the mechanism that links positive convective anomalies in the eastern Pacific to increased shear in the North Atlantic (e.g., Aiyyer and Thorncroft 2006). To make this physical link more robust, some GCM experiments with specified SST anomalies would have to be conducted, however. In the WP, there is also there is a slight northward and eastward shift away from the Philippines in the location of the monsoon trough, likely causing a corresponding shift in the simulated regions of tropical cyclone formation (e.g., Molinari and Vollaro 2013). In the EP, the GPI bias is primarily contributed by the relative humidity bias, while the biases in the dynamical terms are of cancelling signs. Although the model simulates stronger vertical shear, this term is of a lower exponent compared to relative humidity in the GPI. In the NA main development region, the relative errors in the vertical shear and relative humidity terms play the dominant roles for the negative GPI biases. It is likely that the stronger shear in this region is caused by excessive convection in the eastern Pacific, as this link is a well-known effect of the positive SST anomalies in the eastern Pacific associated with El Niño conditions (e.g., Aiyyer and Thorncroft 2006). The stronger shear and low MPI are the main reasons for the negative GPI bias in the NI. Over the Southern Hemisphere, all four terms contributed to the positive GPI error in the SI corresponding to

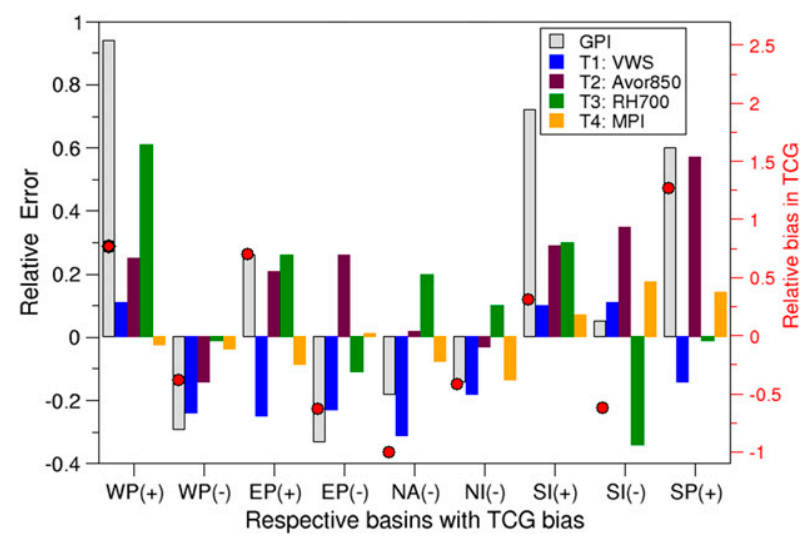

FIG. 11. Estimated relative error of genesis potential index (GPI; gray bar), and individual contributing terms: T1: VWS (blue), T2: Avor850 (maroon), T3: RH700 (green), and T4: MPI (orange) corresponding to the selected regions (Table 3 ) of positive $(+)$ and negative ( - ) TCG biases shown as boxes in Fig. 5, for individual ocean basins. The relative bias in the TCG (as red dots) is also shown on the right $y$ axis. 
the positive TCG bias, although the vorticity and relative humidity bias are the dominant among them. In contrast, the model fails to capture the negative bias in GPI corresponding to negative TCG in the northwest coast of Australia, although the negative contribution of relative humidity to the positive GPI error suggests the influence of simulated drier-than-observed air (Fig. 9Vc, Fig. S2) in inhibiting TCG in this region. In the SP, the positive GPI error relative to positive TCG bias is predominantly contributed by the vorticity term consistent with the stronger vorticity bias in this region (Fig. 9VIb, Fig. S2). It is interesting to note that the contribution of the MPI remains weak or minimal in most of the basins, consistent with Fig. 9 and Fig. S2. The analysis suggests that GPI biases corresponding to TCG biases are predominantly influenced by the relative errors in the vertical wind shear and midlevel relative humidity, while vorticity bias has some region-specific dominance, especially over the SP. These results are quite consistent with the contrasting roles of regional climate conditions in modulating observed TCG frequency over the individual basins (Sharmila and Walsh 2017).

\section{Summary and conclusions}

In this part of this study, the ability of a highresolution $(\sim 40 \mathrm{~km}$ in the horizontal) atmospheric GCM in simulating present-climate global and regional $\mathrm{TC}$ formation rates is systematically assessed. We use the atmospheric component of ACCESS model forced with observed SST and the modified CSIRO-TC tracking scheme is applied to derive TCs from 20 years of model integration.

Overall, the model reproduces the observed presentclimate climatology and interhemispheric asymmetry of global TC formation rates reasonably well, although the model is moderately more TC active than observed in the Southern Hemisphere. The annual cycle of regional TC formation rates over most of the basins (except the NI) is also well captured. In addition, the model can reproduce the interannual variability of TC frequency in the NA and North Pacific basins to some extent, along with capturing the geographical difference in TC formation rates between $\mathrm{El}$ Niño and $\mathrm{La}$ Niña years. The model reproduces the spatial distribution of the annual TCG density moderately well but suffers from notable regional biases over individual ocean basins. For instance, the model highly undersimulates TCG density in the NA basin, and moderately in the EP and eastern half of the SI, while it oversimulates TCG density in the SP, northeast of the $\mathrm{WP}$, and in the western half of the SI compared to the observed.
To investigate the cause of TCG biases, we systematically evaluate a suite of model simulated mean-state large-scale climate conditions that critically modulate the TC formation rates, including the assessment of a multivariate GPI, along with all four contributing components. It is found that the TCG biases identified in this study are closely related to the systematic model biases in the TC-favorable large-scale mean-state dynamical and thermodynamical conditions. For instance, a large meanstate positive model bias of vertical wind shear could inhibit the generation of TC-like vortices in the NA, while a large negative bias in the relative humidity in the EP is consistent with the large negative bias in TCG over these regions. In contrast, the high cyclonic vorticity bias in the SP is concomitant with oversimulated TCG in this region.

The analysis based on GPI relative errors also suggests the consistent influence of the identified large-scale mean-state model biases on the TCG biases. We note a basin-specific influence of the model biases in the governing climate conditions on corresponding biases in the TC formation rates, although mostly influenced by the biases in the large-scale dynamical conditions. However, most of the identified climatological biases (e.g., a high shear bias in the main development region over the NA) are common in recent climate models (Camargo and Wing 2016). It is an ongoing issue that the simulated global TC frequency in recent climate models is extremely sensitive to the details of the convection schemes used in those models (Camargo and Wing 2016), particularly parameterizations of deep convection. For instance, a change in convective parameterization can change the rate of latent heat release at upper levels, causing a change in the meridional temperature gradient and a resulting change in the vertical wind shear through the thermal wind relationship. As Camargo and Wing (2016) state, this is likely to remain an issue until the modeling community is able routinely to run long climate model simulations of TC formation at horizontal resolutions fine enough to remove the need for convective parameterization and to also achieve a good simulation of the observed intensity distribution. Simulations with regional models suggest that this resolution is likely to be less than 5 km (e.g., Knutson et al. 2015). However, resolution and convective parameterizations are not the only factors that influence the simulation of TCs, and work is ongoing to address some of the issues noted here.

The overall quality of TC simulation as demonstrated by this high-resolution ACCESS model utilized here thus enables us to construct idealized model experiments with the goal of understanding the climatic controls on TC formation rates. Hence, in the second part of this work, we will show the results from a series of idealized experiments by employing this same high-resolution model 
but in an aquaplanet configuration (Hayashi and Sumi 1986) to investigate the sensitivity of the global TC formation rates to various systematic changes in SST distribution and the associated large-scale atmospheric circulation. This approach is expected to elucidate the possible mechanisms of a climate theory of $\mathrm{TC}$ formation.

Acknowledgments. This research was funded by the Australian Research Council Discovery Project DP15012272. The authors thank three anonymous reviewers for their constructive comments on the previous version that has improved the quality of the paper. SS acknowledges the present support from the Northern Australia Climate Program (NACP) project at the University of Southern Queensland/Bureau of Meteorology, Australia. SS also thanks Dr. S. Abhik, Prof. Ian Simmonds, and Prof. Suzana Camargo for useful discussions. The climate model used in this study was supplied by the ACCESS modelling team, with the support of the ARC Centre of Excellence for Climate System Science. The simulations and analyses were performed on the National Computational Infrastructure system (https://nci.org.au), supported by the Australian Government. Figures are prepared using the free software NCAR Command Language (NCL) and GRACE. All model outputs are available for analysis on request to the corresponding author.

\section{REFERENCES}

Adler, R. F., and Coauthors, 2003: The version 2 Global Precipitation Climatology Project (GPCP) Monthly Precipitation Analysis (1979-present). J. Hydrometeor., 4, 1147-1167, https://doi.org/ 10.1175/1525-7541(2003)004<1147:TVGPCP > 2.0.CO 2 .

Aiyyer, A. R., and C. Thorncroft, 2006: Climatology of vertical wind shear over the tropical Atlantic. J. Climate, 19, 29692983, https://doi.org/10.1175/JCLI3685.1.

Ballinger, A. P., T. M. Merlis, I. M. Held, and M. Zhao, 2015: The sensitivity of tropical cyclone activity to off-equatorial thermal forcing in aquaplanet simulations. J. Atmos. Sci., 72, 22862302, https://doi.org/10.1175/JAS-D-14-0284.1.

Basher, R. E., and X. Zheng, 1995: Tropical cyclones in the southwest Pacific: Spatial patterns and relationships to Southern Oscillation and sea surface temperature. J. Climate, 8 , 1249-1260, https://doi.org/10.1175/1520-0442(1995)008<1249: TCITSP $>2.0 . \mathrm{CO} ; 2$.

Bell, R., K. Hodges, P. L. Vidale, J. Strachan, and M. Roberts, 2014: Simulation of the global ENSO-tropical cyclone teleconnection by a high-resolution coupled general circulation model. J. Climate, 27, 6404-6422, https://doi.org/10.1175/JCLI-D13-00559.1.

Best, M. J., and Coauthors, 2011: The Joint UK Land Environment Simulator (JULES), model description-Part 1: Energy and water fluxes. Geosci. Model Dev., 4, 677-699, https://doi.org/ 10.5194/gmd-4-677-2011.

Bister, M., and K. A. Emanuel, 1998: Dissipative heating and hurricane intensity. Meteor. Atmos. Phys., 65, 233-240, https:// doi.org/10.1007/BF01030791.
Bruyère, C. L., G. J. Holland, and E. Towler, 2012: Investigating the use of a genesis potential index for tropical cyclones in the North Atlantic basin. J. Climate, 25, 8611-8626, https://doi.org/ 10.1175/JCLI-D-11-00619.1.

Camargo, S. J., and A. A. Wing, 2016: Tropical cyclones in climate models. Wiley Interdiscip. Rev.: Climate Change, 7, 211-237, https://doi.org/10.1002/wcc.373.

— A. G. Barnston, P. J. Klotzbach, and C. Landsea, 2007a: Seasonal tropical cyclone forecasts. WMO Bull., 56, 297-309, https://public.wmo.int/en/bulletin/seasonal-tropical-cycloneforecasts.

A. H. Sobel, A. G. Barnston, and K. A. Emanuel, 2007b: Tropical cyclone genesis potential index in climate models. Tellus, 59A, 428-443, https://doi.org/10.1111/j.1600-0870.2007.00238.x.

$\_,-\ldots$, , and P. J. Klotzbach, 2010: The influence of natural climate variability, and seasonal forecasts of tropical cyclone activity. Global Perspectives on Tropical Cyclones, from Science to Mitigation, 2nd ed., J. C. L. Chan and J. D. Kepert, Eds., 325-362.

- M. K. Tippett, A. H. Sobel, G. A. Vecchi, and M. Zhao, 2014: Testing the performance of tropical cyclone genesis indices in future climates using the HiRAM model. J. Climate, 27, 91719196, https://doi.org/10.1175/JCLI-D-13-00505.1.

Chavas, D. R., K. A. Reed, and J. A. Knaff, 2017: Physical understanding of the tropical cyclone wind-pressure relationship. Nat. Commun., 8, 1360, https://doi.org/10.1038/ s41467-017-01546-9.

Chia, H. H., and C. F. Ropelewski, 2002: The interannual variability in the genesis location of tropical cyclones in the northwest Pacific. J. Climate, 15, 2934-2944, https://doi.org/ 10.1175/1520-0442(2002)015<2934:TIVITG >2.0.CO;2.

Dee, D., and Coauthors, 2011: The ERA-Interim reanalysis: Configuration and performance of the data assimilation system. Quart. J. Roy. Meteor. Soc., 137, 553-597, https://doi.org/ 10.1002/qj.828.

Edwards, J. M., and A. Slingo, 1996: Studies with a flexible new radiation code. I: Choosing a configuration for a large-scale model. Quart. J. Roy. Meteor. Soc., 122, 689-719, https:// doi.org/10.1002/qj.49712253107.

Efron, B., and R. J. Tibshirani, 1993: An Introduction to the Bootstrap. Chapman and Hall, $436 \mathrm{pp}$.

Emanuel, K., 2003: Tropical cyclones. Annu. Rev. Earth Planet. Sci., 31, 75-104, https://doi.org/10.1146/annurev.earth.31.100901.141259.

, 2010: Tropical cyclone activity downscaled from NOAACIRES reanalysis, 1908-1958. J. Adv. Model. Earth Syst., 2, 1, https://doi.org/10.3894/JAMES.2010.2.1.

- , and D. S. Nolan, 2004: Tropical cyclone activity and the global climate system. Extended Abstracts, 26th Conf. on Hurricanes and Tropical Meteorology, Miami, FL, Amer. Meteor. Soc., 240-241.

Felton, C. S., B. Subrahmanyam, and V. S. N. Murty, 2013: ENSOmodulated cyclogenesis over the Bay of Bengal. J. Climate, 26, 9806-9818, https://doi.org/10.1175/JCLI-D-13-00134.1.

Hayashi, Y.-Y., and A. Sumi, 1986: The 30-40 day oscillations simulated in an "aqua planet" model. J. Meteor. Soc. Japan, 64, 451-467, https://doi.org/10.2151/jmsj1965.64.4_451.

Horn, M., and Coauthors, 2014: Tracking scheme dependence of simulated tropical cyclone response to idealized climate simulations. J. Climate, 27, 9197-9213, https://doi.org/10.1175/ JCLI-D-14-00200.1.

Kanamitsu, M., W. Ebisuzaki, J. Woollen, S.-K. Yang, J. J. Hnilo, M. Fiorino, and G. L. Potter, 2002: NCEP-DOE AMIP-II Reanalysis (R-2). Bull. Amer. Meteor. Soc., 83, 1631-1643, https://doi.org/10.1175/BAMS-83-11-1631. 
Khairoutdinov, M., and K. A. Emanuel, 2013: Rotating radiativeconvective equilibrium simulated by a cloud-resolving model. J. Adv. Model. Earth Syst., 5, 816-825, https://doi.org/10.1002/ 2013MS000253.

Knapp, K. R., M. C. Kruk, D. H. Levinson, H. J. Diamond, and C. J. Neumann, 2010: The International Best Track Archive for Climate Stewardship (IBTrACS): Unifying tropical cyclone data. Bull. Amer. Meteor. Soc., 91, 363-376, https://doi.org/ 10.1175/2009BAMS2755.1.

Knutson, T. R., and Coauthors, 2010: Tropical cyclones and climate change. Nat. Geosci., 3, 157-163, https://doi.org/10.1038/ngeo779.

— J. J. Sirutis, M. Zhao, R. E. Tuleya, M. Bende, G. A. Vecchi, G. Villarini, and D. Chavas, 2015: Global projections of intense tropical cyclone activity for the late 21st century from dynamical downscaling of CMIP5/RCP4.5 scenarios. J. Climate, 28, 72037224, https://doi.org/10.1175/JCLI-D-15-0129.1.

Kossin, J. P., S. J. Camargo, and M. Sitkowski, 2010: Climate modulation of North Atlantic hurricane tracks. J. Climate, 23, 3057-3076, https://doi.org/10.1175/2010JCLI3497.1.

Kuleshov, Y., L. Qi, R. Fawcett, and D. Jones, 2008: On tropical cyclone activity in the Southern Hemisphere: Trends and the ENSO connection. Geophys. Res. Lett., 35, L14S08, https:// doi.org/10.1029/2007GL032983.

Lock, A. P., A. R. Brown, M. R. Bush, G. M. Martin, and R. N. B. Smith, 2000: A new boundary layer mixing scheme. Part I: Scheme description and single-column model tests. Mon. Wea. Rev., 128, 3187-3199, https://doi.org/10.1175/1520-0493(2000) $128<3187$ :ANBLMS $>2.0$.CO;2.

Merlis, T. M., M. Zhao, and I. M. Held, 2013: The sensitivity of hurricane frequency to ITCZ changes and radiatively forced warming in aquaplanet simulations. Geophys. Res. Lett., 40, 4109-4114, https://doi.org/10.1002/grl.50680.

Molinari, J., and D. Vollaro, 2013: What percentage of western North Pacific tropical cyclones form within the monsoon trough? Mon. Wea. Rev., 141, 499-505, https://doi.org/10.1175/ MWR-D-12-00165.1.

Murakami, H., and B. Wang, 2010: Future change of North Atlantic tropical cyclone tracks: Projection by a $20-\mathrm{km}-\mathrm{mesh}$ global atmospheric model. J. Climate, 23, 2699-2721, https:// doi.org/10.1175/2010JCLI3338.1.

- , and Coauthors, 2012: Future changes in tropical cyclone activity projected by the new high-resolution MRI-AGCM. J. Climate, 25, 3237-3260, https://doi.org/10.1175/JCLI-D11-00415.1.

— and 5 hurricanes in the high-resolution GFDL HiFLOR coupled climate model. J. Climate, 28, 9058-9079, https://doi.org/ 10.1175/JCLI-D-15-0216.1.

Reed, K. A., J. T. Bacmeister, N. A. Rosenbloom, M. F. Wehner, S. C. Bates, P. H. Lauritzen, J. E. Truesdale, and C. Hannay, 2015: Impact of the dynamical core on the direct simulation of tropical cyclones in a high-resolution global model. Geophys. Res. Lett., 42, 3603-3608, https://doi.org/10.1002/ 2015 GL063974.

Roberts, M. J., and Coauthors, 2015: Tropical cyclones in the UPSCALE ensemble of high-resolution global climate models. J. Climate, 28, 574-596, https://doi.org/10.1175/ JCLI-D-14-00131.1.

Shaevitz, D. A., and Coauthors, 2014: Characteristics of tropical cyclones in high-resolution models of the present climate.
J. Adv. Model. Earth Syst., 6, 1154-1172, https://doi.org/ 10.1002/2014MS000372.

Sharmila, S., and K. J. E. Walsh, 2017: Impact of large-scale dynamic versus thermodynamic climate conditions on contrasting tropical cyclone genesis frequency. J. Climate, $\mathbf{3 0}$, 8865-8883, https://doi.org/10.1175/JCLI-D-16-0900.1.

Tang, B., and K. Emanuel, 2010: Midlevel ventilation's constraint on tropical cyclone intensity. J. Atmos. Sci., 67, 1817-1830, https://doi.org/10.1175/2010JAS3318.1.

Taylor, K. E., 2001: Summarizing multiple aspects of model performance in a single diagram. J. Geophys. Res., 106, 71837192, https://doi.org/10.1029/2000JD900719.

Tippett, M. K., S. J. Camargo, and A. H. Sobel, 2011: A Poisson regression index for tropical cyclone genesis and the role of large-scale vorticity in genesis. J. Climate, 24, 2335-2357, https://doi.org/10.1175/2010JCLI3811.1.

Vitart, F., and Coauthors, 2014: Seasonal forecasts. Topic 5.2, International Workshop on Tropical Cyclones VIII Report, WMO, 29 pp., http://www.wmo.int/pages/prog/arep/wwrp/ new/documents/Topic5.2_SeasonalForecasts.pdf.

Walsh, K., 2019: Climate, climate change, and risk. Hurricanes Risk, Vol. 1, J. M. Collins and K. J. E. Walsh, Eds., Springer, in press.

- M. Fiorino, C. Landsea, and K. McInnes, 2007: Objectivelydetermined resolution-dependent threshold criteria for the detection of tropical cyclones in climate models and reanalyses. J. Climate, 20, 2307-2314, https://doi.org/10.1175/JCLI4074.1.

— , and Coauthors, 2016: Tropical cyclones and climate change. Wiley Interdiscip. Rev.: Climate Change, 7, 65-89, https:// doi.org/10.1002/wcc.371.

- S. Sharmila, M. Thatcher, S. Wales, S. Utembe, and A. Vaughan, 2019: Real world and tropical cyclone world. Part II: Sensitivity of tropical cyclone formation to uniform and meridionally varying SSTs under aquaplanet conditions. $J$. Climate, 33, 1473-1486, https://doi/org/10.1175/JCLI-D-190079.1

Walters, D. N., and Coauthors, 2017: The Met Office Unified Model Global Atmosphere 6.0/6.1 and JULES Global Land 6.0/6.1 configurations. Geosci. Model Dev., 10, 1487-1520, https://doi.org/10.5194/gmd-10-1487-2017.

Wang, B., and J. C. Chan, 2002: How strong ENSO events affect tropical storm activity over the western North Pacific. J. Climate, 15, 1643-1658, https://doi.org/10.1175/1520-0442(2002)015<1643: HSEEAT > 2.0.CO;2.

Wehner, M. F., K. A. Reed, and C. M. Zarzycki, 2017: Highresolution multi-decadal simulation of tropical cyclones. Hurricanes and Climate Change, Vol. 3, J. M. Collins and K. J. E. Walsh, Eds., Springer, 187-211.

Wilson, D. R., A. C. Bushell, A. M. Kerr-Munslow, J. D. Price, and C. J. Morcrette, 2008: PC2: A prognostic cloud fraction and condensation scheme. I: Scheme description. Quart. J. Roy. Meteor. Soc., 134, 2093-2107, https://doi.org/10.1002/qj.333.

Wood, N., and Coauthors, 2014: An inherently mass-conserving semi-implicit semi- Lagrangian discretization of the deepatmosphere global non-hydrostatic equations. Quart. J. Roy. Meteor. Soc., 140, 1505-1520, https://doi.org/10.1002/qj.2235.

Yoshida, K., M. Sugi, R. Mizuta, H. Murakami, and M. Ishii, 2017: Future changes in tropical cyclone activity in high-resolution large-ensemble simulations. Geophys. Res. Lett., 44, 99109917, https://doi.org/10.1002/2017GL075058. 